\title{
El mosaico del Auriga de la villa romana de El Val (Alcalá de Henares, Madrid) y las carreras de carros en el entorno complutense
}

\author{
Sebastián Rascón Marqués * \\ ANTONIO MÉNDEZ MADARIAGA *ᄎ \\ Ana Lucia Sánchez MONTES
}

\section{INTRODUCCIÓN}

\subsection{Situación de la villa de El Val}

La villa romana de El Val se encuentra al NE de Alcalá de Henares, en el espacio que enmarcan la antigua carretera nacional II Madrid-Barcelona por el Norte y el río Henares por el Sur. El yacimiento está a la altura del kilómetro 32,200 de la primera, de la que dista unos $200 \mathrm{~m}$ mientras que son $400 \mathrm{~m}$ los que la separan del río (fig. 1).

Se asienta sobre un terreno sedimentario en la última terraza del río, una zona fácilmente inundable y muy apta para la agricultura por su fertilidad, horizontalidad y buenas posibilidades de incorporar regadíos.

Los alrededores de la zona de El Val, hoy convertidos en espacios urbanos, han sido tradicionalmente dehesas. Además la villa dista tan sólo $2 \mathrm{~km}$ de las áreas pantanosas ubicadas bajo la actual Alcalá de Henares, saneadas desde la época del Cardenal Cisneros, cuando se acometieron las obras de infraestructura para la ciudad y la Universidad'.

* TEAR, Alcalá de Henares

* Consejeria de Educación y Cultura. Comunidad de Madrid.

Diversas referencias históricas a los problemas ocasionados en la Alcalá bajomedieval y 


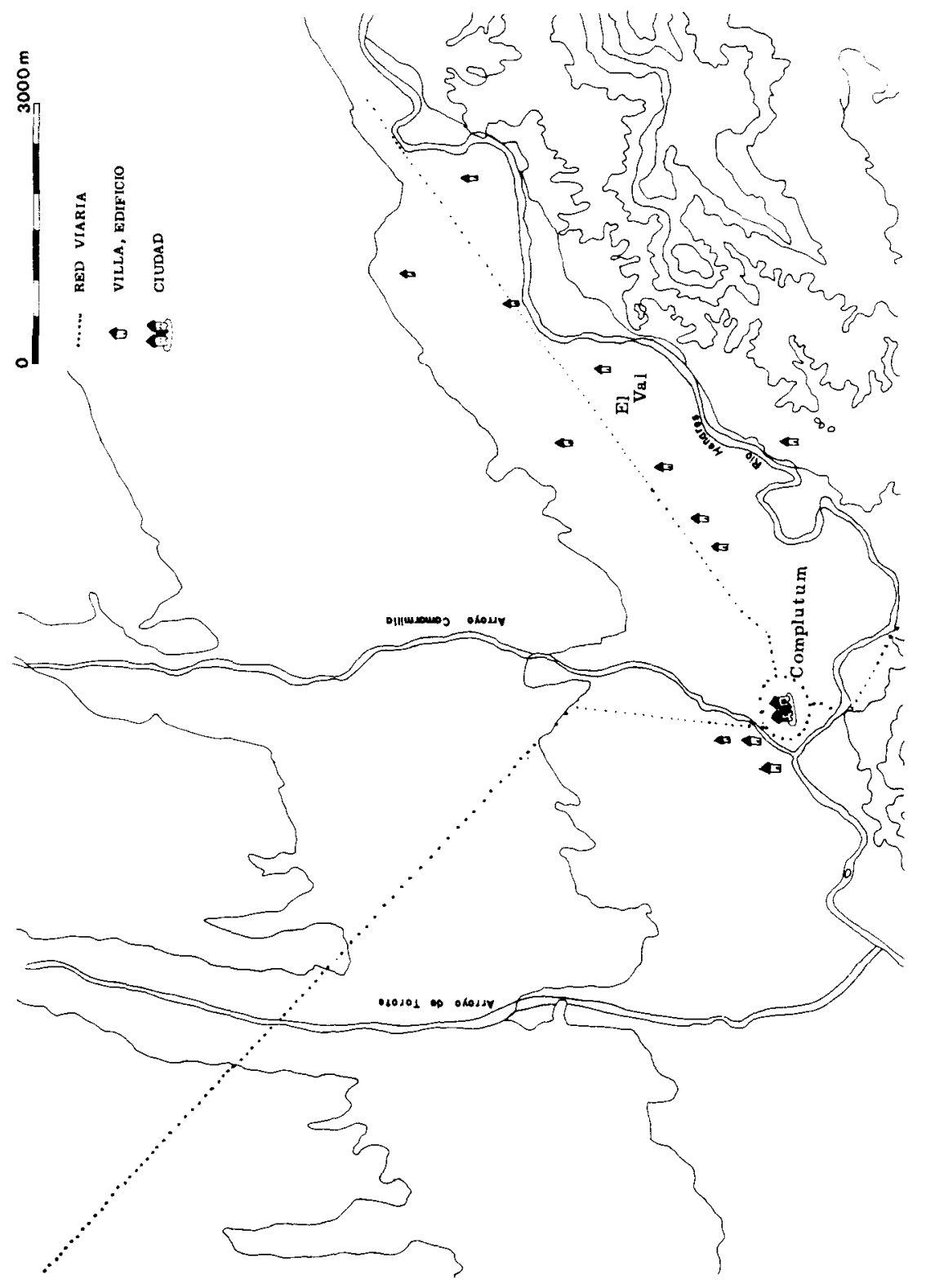

Fig. 1. Situación de la villa de "El Val». 
A

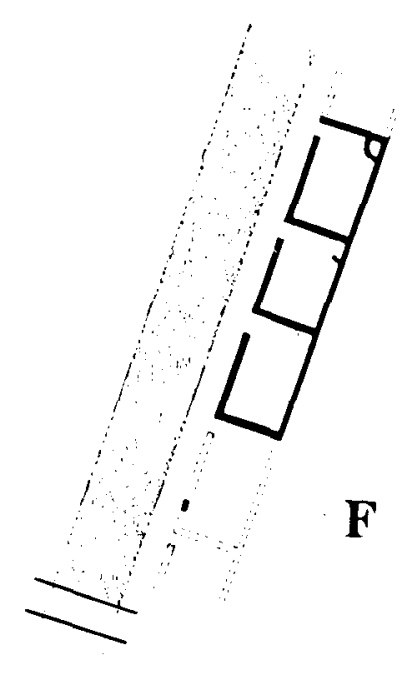

B
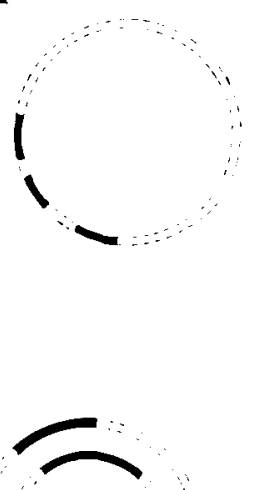

E

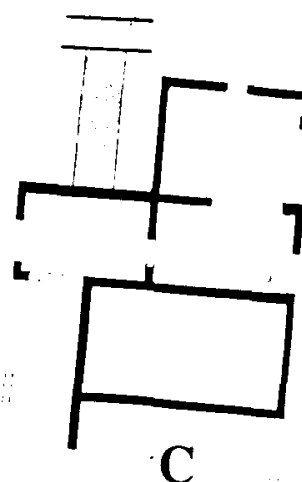

$\frac{2}{\frac{\pi}{2}}$

$\overline{\underline{v}}$

8

$\stackrel{\infty}{5}$

Q

\&

$\frac{0}{0}$
$\frac{0}{0}$
$\frac{0}{0}$
$\frac{0}{0}$
$\frac{\pi}{2}$

i

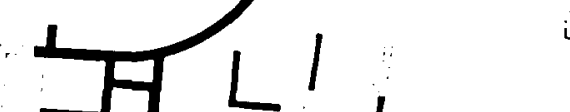

D
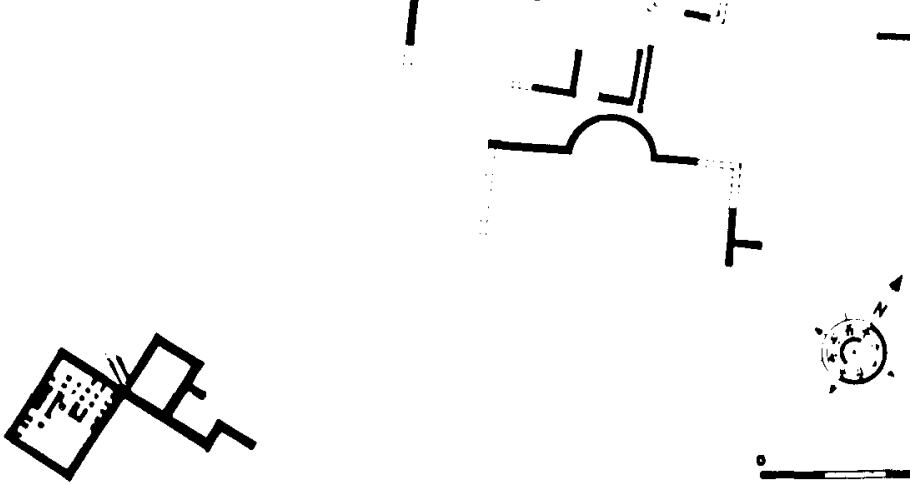


\subsection{Características arqueológicas de la villa de El Val}

Sobre la villa ya hay una cierta bibliografía, a la que remitimos para un mejor conocimiento de la misma ${ }^{2}$. Basta ahora mencionar que se ha intervenido en ella en diversas compañas en 1970, 1974, 1985, 1986, 1987, 1988, 1989 y 1990, siempre según procedimiento de urgencia. Hoy en día la mayor parte de las estructuras están dentro de una parcela propiedad del Ayuntamiento de Alcalá de Henares, que en la actualidad se encuentra convenientemente cercada. Igualmente se ha procedido a la plantación de arbolado alrededor de dichas estructuras, en zonas que no las afectan con la idea de crear un futuro parque donde hacer visitables las ruinas. Todos estos trabajos, desarrollados desde 1985 hasta la fecha, contaron como base con el equipo arqueológico del Taller Escuela de Arqueología y Rehabilitación del Ayuntamiento de Alcalá de Henares, en cuyas instalaciones se realizan actualmente los trabajos de conservación de los pavimentos musivos, así como con la colaboración del Departamento de Arqueología de la Comunidad de Madrid.

El yacimiento ha llegado a nosotros en muy mal estado de conservación. Podemos decir, sin embargo, que se definen tres fases en el mismo: la primera altoimperial, que se inicia en el siglo 1 y termina en un monumento impreciso; la segunda, bajoimperial, comienza el tercer cuarto del siglo III y se prolonga hasta en torno al año 400 d.C., aunque después de esta fecha aún se desarrolla cierto tipo de ocupación. Por último, hay un tercer momento en que parte de la vecina necrópolis de época visigoda del Camino de los Afligidos se instala sobre una zona concreta de la villa, reaprovechando además sus materiales constructivos y realizando peque-

moderna por crecidas e inundaciones en PéREz GARCíA, R., "Complutum pantanoso", Actas del II EHHVH. Alcalá de Henares 1990, págs. 43-53; págs- 44-45.

2 Fernandez-Galiano Ruiz, D., Carta Arqueológica de Alcalá de Henares y su Partido. Colección Universitaria, 2. Alcalá de Henares 1976. Fernández-Galiano Ruiz, D., Complutum I. Excavaciones. EAE, 134. Madrid 1984. Fernández-Galiano Ruiz, D., Complutum II. Mosaicos. EAE, 135. Madrid 1984. Méndez Madariaga, A. y Rascon Maroues, S., "La villa romana de el Val: un acercamiento a su estructura y a su cronología", Actas del 1 EHHVH, 1988. Alcalá de Henares, 7, págs. 499-511. Méndez Madariaga, A. y Rascón Marqués, S., Los visigodos en Alcalá de Henares. CJ, 1. Alcalá de Henares 1989. Méndez Madariaga, A., y Rascón Marqués, S., "La villa romana de El Val (Alcalá de Henares)", RA, 101. Madrid 1989, págs. 50-58. MONdejar Majuelos, J. A., «La extracción de un mosaico de la villa romana de El Val. Alcalá de Henares (Madrid)", Patina, 5. 1991, págs. 29-32. Rascón Marqués y Méndez Madariaga, A., "Excavación de un mosaico de tema circense en la vilia romana de EI Val (Alcalá de Henares)", AACC, II. Alcalá de Henares 1988, págs. 133-134. Rascon Marqués, S.; Méndez Madariaga, A. y Diaz del. Rio ESPAÑoL, P., «La reocupación del mosaico del Auriga victorioso en la villa romana de El Val (Alcalá de Henares). Un estudio de microespacio". APECM, 1. Madrid 1990. TEAR, Arqueología en Alcalá de Henares. Alcalá de Henares 1991. 
ñas reformas en la distribución del espacio. Todo ello, sin embargo, no se refleja en una estratigrafía bien definida salvo en lugares determinados, ya que la erosión y la acción humana han jugado un papel determinante en el estado de conservación del yacimiento. Una de estas zonas privilegiadas a las que nos referimos es la llamada Área C, con la sala del Auriga, que hemos interpretado como el oecus (fig. 2). Por razones de espacio omitiremos desarrolar aquí la estratigrafía de dicha sala, que puede estudiarse en la bibliografía citada. Sin embargo, la interpretación de la misma es la siguiente (fig. 3)

- Un nivel de aterrazamiento compuesto por materiales de la primera fase del yacimiento (mediados del siglo I d.C. hasta pleno siglo III) que se practicó para levantar las estructuras bajoimperiales (nivel VI).

- La sala del Auriga propiamente dicha, correspondiente a la villa bajoimperial, con una cronología entre el último cuarto del siglo III y en torno al 400 d.C.: niveles II, III y V.

- Una reocupación inmediatamente posterior al abandono del edificio por sus propietarios, que se manifiesta en la práctica de una serie de intervenciones (postes, un horno) que alteran el pavimento original romano. Los restos materiales utilizados por estas gentes son los que quedan en el nivel IV, sellados posteriormente por el V.

La documentación de estas tres ocupaciones básicas ha sido posible gracias a la completa excavación de la sala, que ha supuesto:

- La excavación, a partir de una primera cata de 5 por $5 \mathrm{~m}$, de toda un área que denominamos $\mathrm{C}$.

- La limpieza, consolidación y arranque del pavimento musivo para su restauración en las instalaciones del Taller Escuela de Arqueología y Rehabilitación de Alcalá de Henares.

- La excavación en área del rudus del mosaico.

- La excavación de cada uno de los postes que perforan el mosaico. Estos postes rompian también el nivel VI de aterrazamiento sobre el que descansa el rudus, por lo cual la mejor forma de documentarlos es con posterioridad a la excavación de este último.

- La excavación de una cata de 2 por $1 \mathrm{~m}$ en el nivel sobre el que se asentaba el rudus.

Este artículo tratará exclusivamente sobre la ocupación de la sala en 


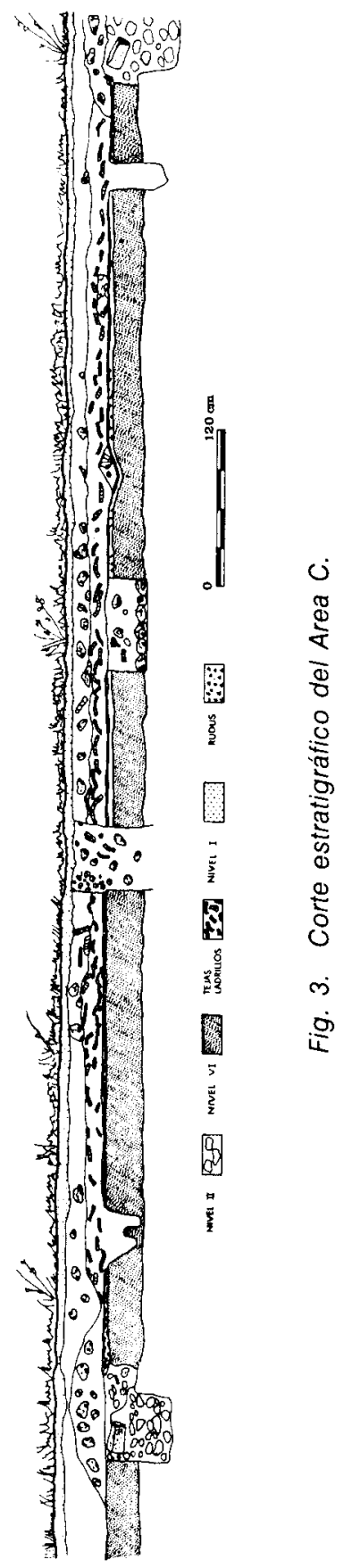


el segundo momento. Para un estudio exhaustivo del tercero, consultar bibliografía citada ${ }^{3}$.

Por último, sólo mencionaremos la interesante posición de la villa de El Val en relación con la vecina Complutum, de la que sólo dista $4 \mathrm{Km}$ y con la vía Emerita Augusta-Caesaraugusta.

\section{EL MOSAICO DEL AURIGA}

\section{II.1. Descripción (figs. 4, 5 y 6)}

Las dimensiones originales del pavimento son de 10 por $15 \mathrm{~m}$. Sin embargo, no se conserva integramente, pues la mitad inferior está muy deteriorada y tan sólo algunos fragmentos aislados de opus tessellatum se mantienen aún sobre el rudus. Una conducción de agua realizada en los años 70 atraviesa la habitación longitudinalmente, cortando al mosaico en toda su extensión. Otro desperfecto que se añade a los anteriores es el proceso de transformación que sufre la sala una vez es abandonado por sus propietarios originales. A comienzos del siglo $\vee$ d.C. un grupo de gentes se instala en ella y construye una gran cabaña, perforando el suelo con un total de cincuenta y siete hoyos.

Todo lo anterior reduce la parte conservada de opus tessellatum a unos 90 metros cuadrados.

El mosaico se estructura en las siguientes partes:

- Il.1.1. Banda de enlace de color ocre, de ocho centímetros en los lados largos y 10 en los cortos. 138).

- 11.1.2. Listel de doble hilera de teselas de color negro (RGDG

- II.1.3. Orla con campo de parejas de peltas (RGDG 455, fig. 7). Nuestras peltas contienen una variante con respecto a los modelos más habituales, como es el hecho de que cada una tenga un apéndice consistente en una hoja en forma de corazón (RGDG 100D). Los motivos son negros sobre fondo crema, y rellenando los espacios vacios aparecen unos lóbulos de color rojo.

- II.1.4. Listel de doble hilera de color negro (RGDG 138).

- II.1.5. Banda de cuatro teselas (RGDG 140) de color crema.

3 Rascón Marqués, S.; Méndez Madariaga, A. y díaz del Rio Español, P., Op. cit. 


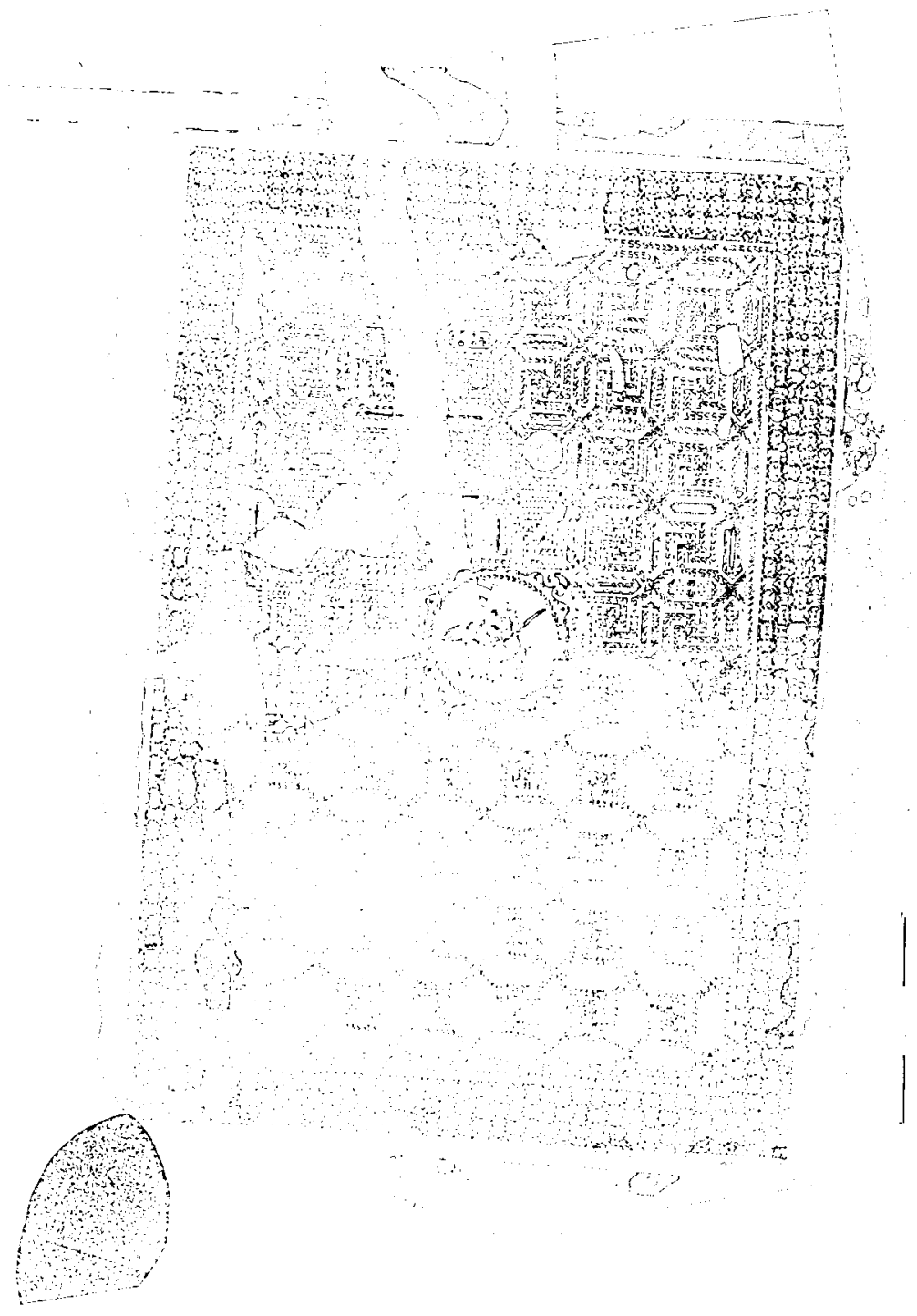

Fig. 4. Plano del mosaico del Auriga. 


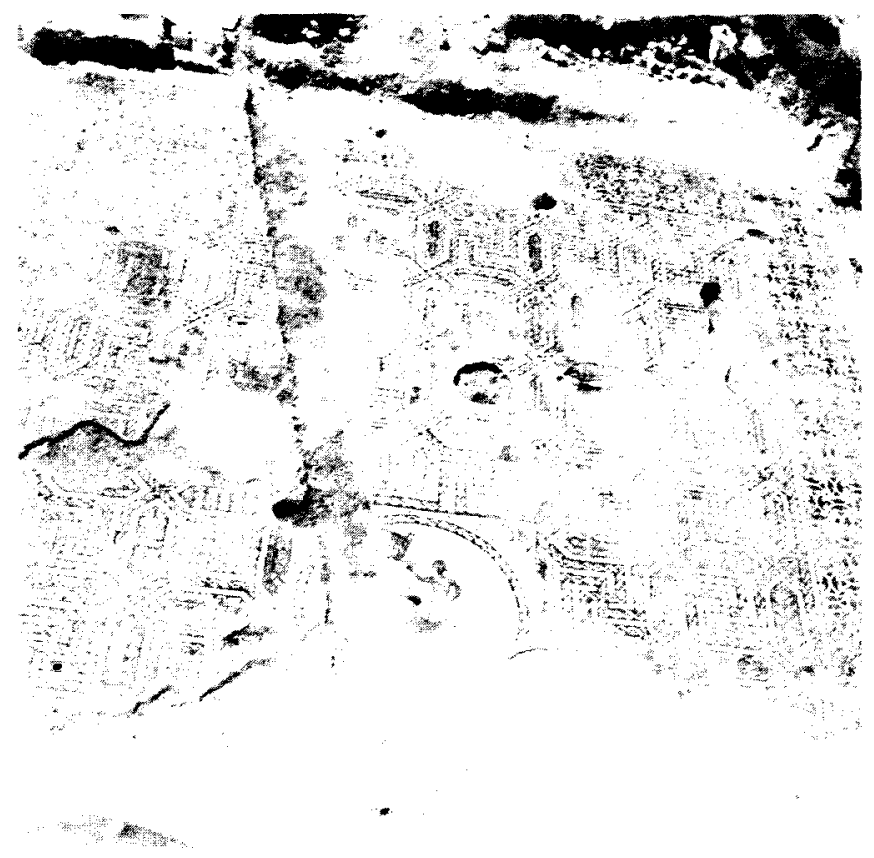

Fig. 5. Vista general del mosaico del Auriga.

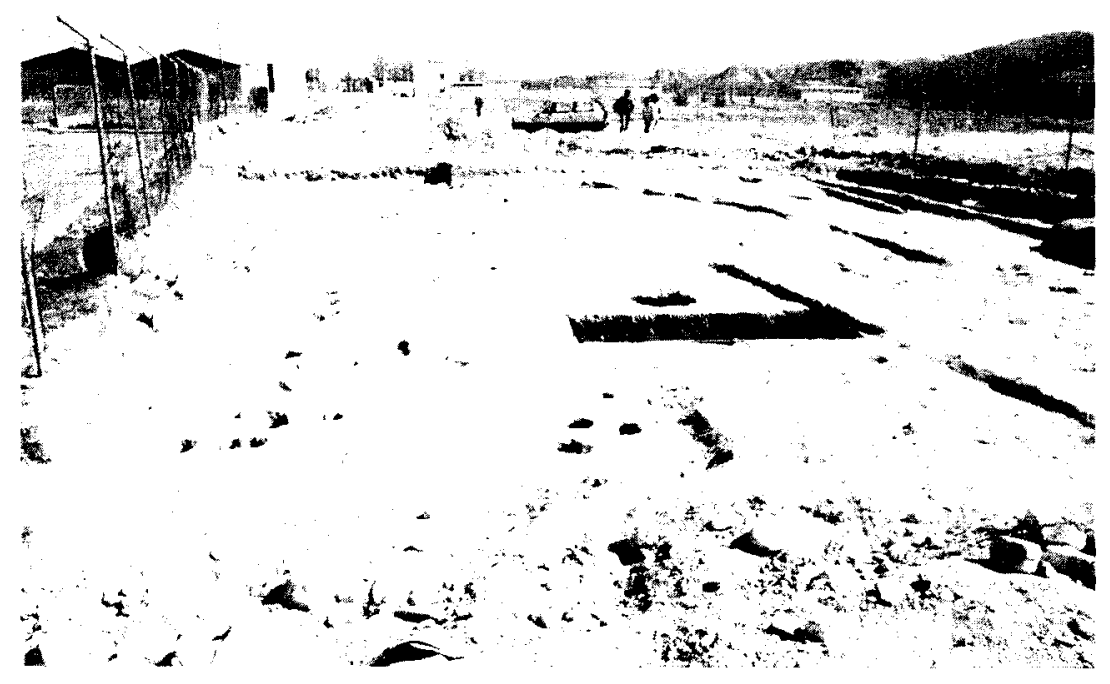

Fig. 6. Vista general del mosaico del Auriga. 


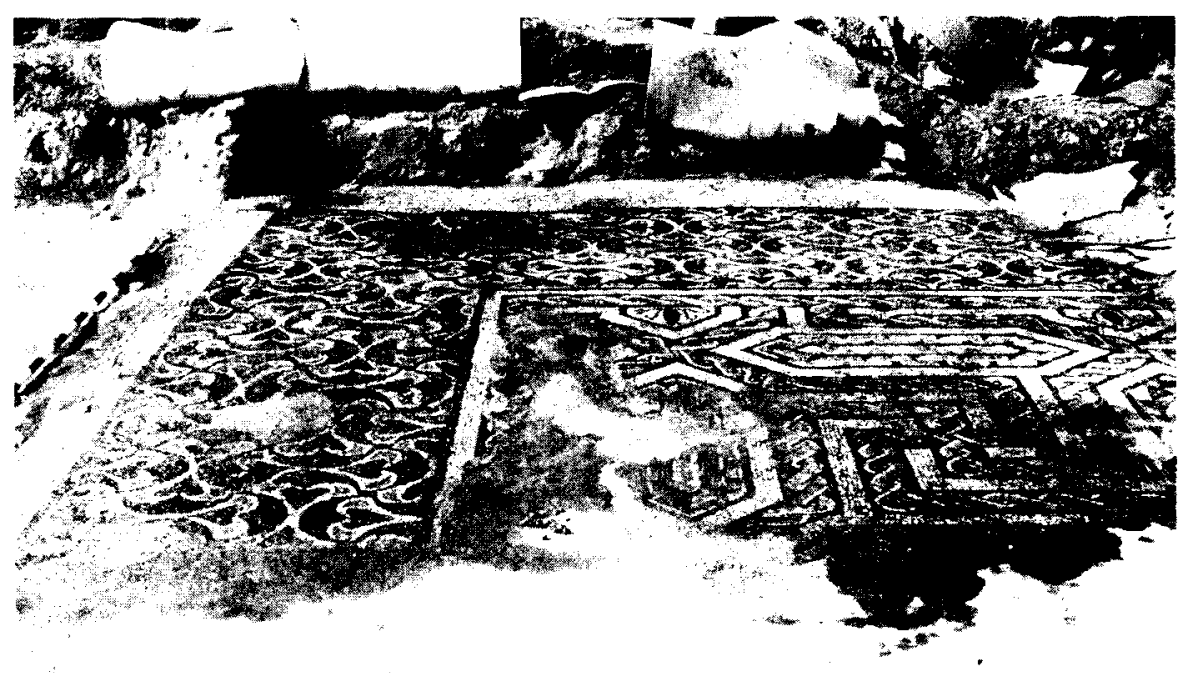

Fig. 7. Detalle del campo de peltas.

- II.1.6. Orla constituida por cable de dos cabos (RGDG 194), siendo cada uno de cinco hileras de teselas. La primera y la quinta son siempre negras, pero las tres centrales van cambiando sus colores por tramos, alternando el blanco con el ocre, el rojo y el gris.

- II.1.7. Campo geométrico de meandros de esvásticas con hexágonos (fig. 8). El meandro lo constituye una orla rellena con cable de dos cabos (RGDG 194), idéntica a la comentada en II.1.6. Otra denominación para este campo, según el RGDG, sería la de octógonos secantes y adyacentes combinados en un meandro de esvásticas (RGDG 358).

La mayoría de las veces la decoración de estos hexágonos es geométrica, pero también puede ser vegetal o incluso figurada. El número total de hexágonos que contenía el mosaico es de ciento treinta y uno, de los que sólo sesenta y cuatro están íntegros o permiten esbozar una reconstrucción interna. Todos los hexágonos son distintos, pues aunque algunos coinciden en su esquema e incluso en su dibujo, el colorido es diferente. Los hemos numerado de arriba a abajo y de izquierda a derecha para una mayor comodidad descriptiva, organizándolos en cuatro grupos, que responden a las siguientes características: 

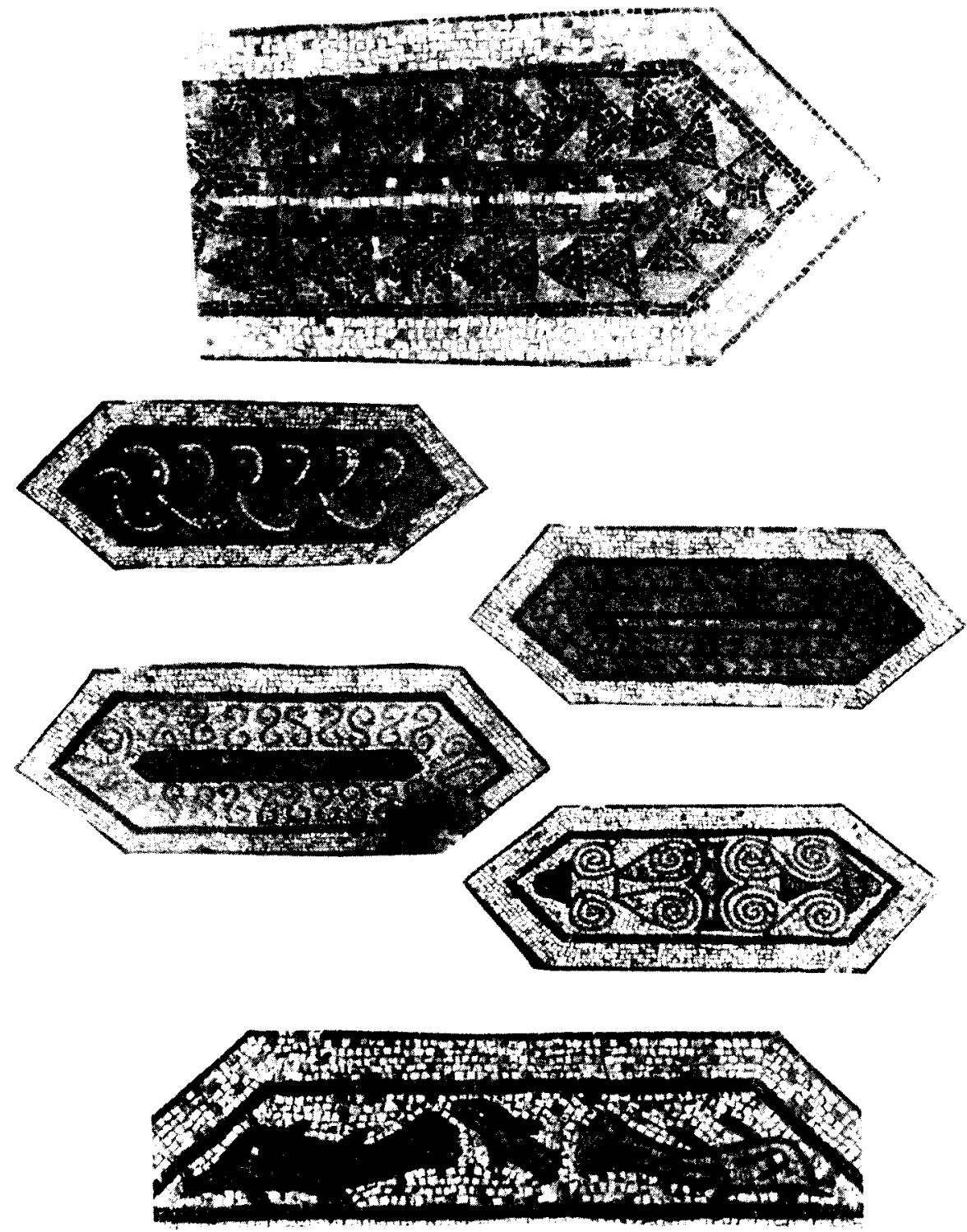

Fig. 8. Diversos tipos de hexágonos. 
A. Hexágonos con un elemento longitudinal en su centro, en torno al cual circunvalan diversos motivos. Son los números $1,2,3,4,5,6,7,8$, $9,10,11,12,13,14,15,17,18,19,20,21,23,24,25,26,27,28,29$, $30,31,32,33,34,36,37,38,39,40,42,43,44,45,46,48,49,50,51$, $52,53,54,55,61,64$.

Los motivos que giran en torno al vástago central pueden ser cables de dos cabos, grecas fraccionadas, triángulos o incluso elementos vegetales.

B. Hexágonos con elementos figurados: números 16, 60, 66 y 72 . Son cráteras acompañadas por complementos vegetales, salvo el número 60 , que contiene tres delfines muy esquematizados, uno de color rojo y dos de color gris, con los detalles que definen su anatomía en negro. Las cráteras se rellenan de color gris.

C. Hexágonos con elementos transversales: números 56, 57, 62 y 92. Dichos elementos son de tipo vegetal (hojas) o cables de doble cabo.

D. Otros: números $58,59,63,65,68,69,73,105$ y 118 . Responden a una iconografía más heterogénea, que incluye nudos de Salomón, arcos y gallonados.

Los colores que se emplean en los hexágonos se mezclan con una libertad equiparable a la que se observa en el rellano de los cables descritos más arriba. Los fondos son de teselas crema, pero entre éstas se combinan otras amarillas o rojas. Los motivos desarrollados combinan con gran libertad el rojo, el amarillo, el negro, el gris y el crema, siempre en piedra y sin buscar otra cosa que un correcto efecto de conjunto, sin descender nunca a buscar una calidad de detalle.

- Il.1.8. Emblema de 2,30 por 2,30 m (fig. 9, 10 y 11), que se estructura por medio de un círculo inscrito en un cuadrado. El círculo viene definido por una orla de cable de dos cabos. Cada uno tiene cinco hileras de teselas, uno de ellos en negro-rojo-rojo-blanco y negro y el otro en negro-amarillo-amarillo-blanco-negro, ambos sobre fondo negro. De las cuatro esquinas que quedan libres en el interior del cuadrado sólo una se conserva íntegra. Las otras han desaparecido, y de ellas sólo restan parte de unos motivos florales que nos permiten suponer su identidad con el conservado. Éste es una pelta de bordes negros sobre fondo crema, que enmarca en su interior un núcleo rojo orlado en gris. Los bordes negros se prolongan para constituir un tallo que se extiende por los recovecos que quedan sin decorar, salpicado por numerosas hojas grises de aspecto fusiforme.

Dentro del círculo se inscribe un auriga vencedor montado en su quadriga. El conjunto se nos presenta en una perspectiva de tres cuartos que 

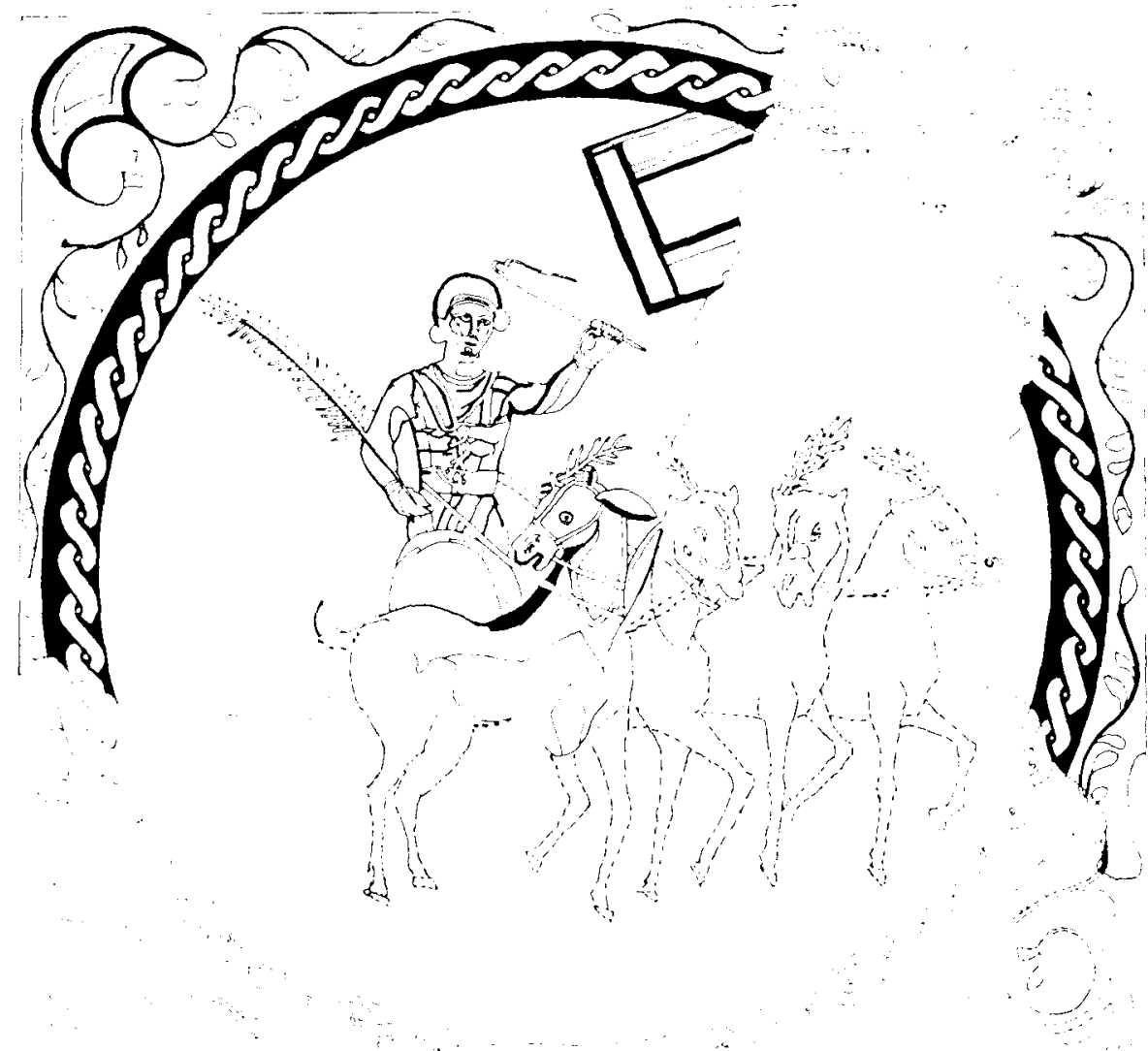

Fig. 9. Emblema del mosaico del Auriga.

afecta a los caballos, ya que el personaje y la caja del carro están girados para que podamos contemplarlos de frente. Desgraciadamente, la mitad inferior del emblema está deteriorada hasta tal punto que no se conservan las teselas, y la zanja que recorre el mosaico de parte a parte ha arrasado casi por completo a tres de los caballos, de los que sólo quedan el hocico de uno y el cuello y la pequeña palma frontal de otro. También ha afectado la zanja a un gran cuadrado que planea sobre el auriga, cuadrado que se divide en bandas de distintos colores (negro, rojo, gris, azul celeste, amarillo y crema) y del que desconocemos su identificación concreta.

El auriga está de frente al espectador, aunque la cabeza se ladea suavemente buscando los tres cuartos. El rostro es de un cuidadoso de- 


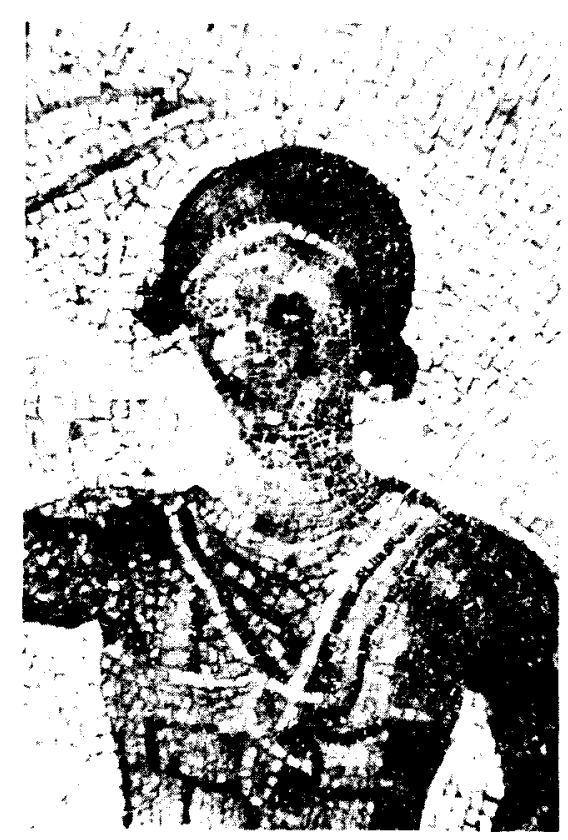

Fig. 10. Detalle del Auriga.

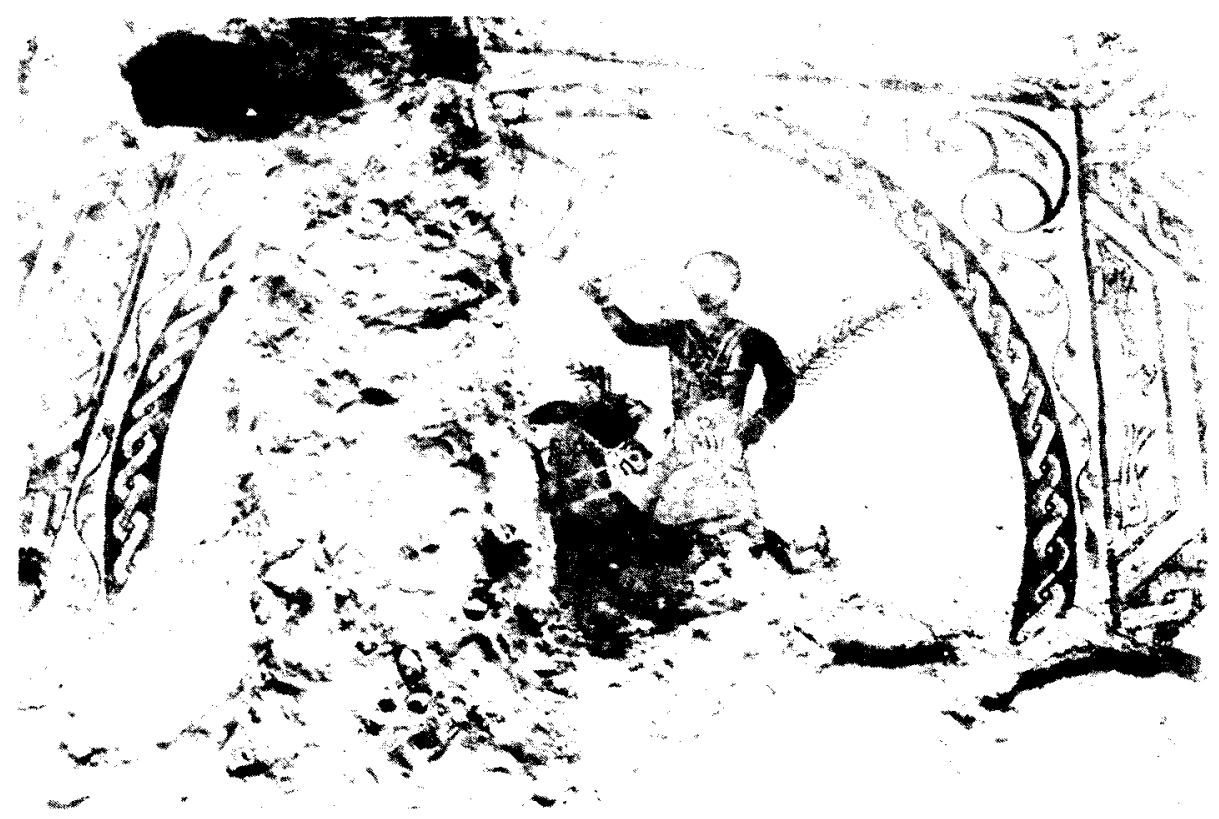

Fig. 11. Emblema. 
tallismo si se compara con otros mosaicos bajoimperiales del entorno complutense, donde unas bruscas líneas rectas indican ojos, nariz y boca (es el caso, por ejemplo, del conjunto de representaciones figuradas de la Casa de Baco ${ }^{4}$ ). En el caso del auriga los degradados buscan un efecto pictórico en la composición, aunque las teselas están algo oscurecidas, probablemente por el efecto del fuego, y no nos es posible apreciar totalmente la sensación que el artista nos quiso transmitir. En el rostro sobresalen los ojos, grandes, hieráticos y cargados de la majestad del vencedor. La cabeza se toca con un casquete hemiesférico con sendas volutas a los lados.

Una palma reposa sobre el brazo izquierdo del auriga, mientras que la mano derecha se levanta alzando el látigo en señal de victoria. Con gran realismo se resuelve el torso, ceñido por su habitual vestimenta, que incluye una flamante túnica verde de mangas largas con galones rojos sobre los hombros, mientras que el pecho y el vientre se rodean con la habitual faja de tiras anudadas al frente. En la cintura, un ancho cinto recibe también a las riendas que lo envuelven, uniéndolo definitivamente con sus caballos. Un faldellín de ptereuges remata el conjunto.

La gama cromática empleada en el auriga es mucho más rica que la utilizada en el campo geométrico. Es además más precisa en su uso. Los colores son blanco, negro, gris, gris oscuro, pardo, rojo oscuro, crema, ocre, amarillo, rosado y azul celeste en piedra, además de tres tonalidades de verde azulado y una de rojo en pasta vítrea, que se emplean para la chaqueta y las palmas.

Bajo el cochero, la caja del carro se resuelve con un fondo amarillo orlado por una banda negra y otra gris.

Respecto a los caballos, ya hemos dicho que sólo se conserva el hocico del funalis derecho y casi íntegro, a excepción de las patas, el izquierdo, así como el cuello y un penacho del iugalis izquierdo. El color de base empleado es un pardo, con el hocico en azul celeste. El ojo se ha representado como un círculo negro relleno de blanco y con una tesela negra en el interior. Los ejecutores del mosaico no presentaron excesiva atención a los detalles anatómicos de los animales, sugiriendo sus volúmenes por medio de unas sombras negras. Todos los caballos irían coronados con una pequeña palma, sí como ornamentados con un adorno colgante bajo el cabezal, que sólo se conserva en el funalis izquierdo.

\footnotetext{
4 Feanandez-Galiano Ruiz, D., Complutum II. Láms. LXXII, LXXIV, XXVIII, LXXIX, LXXX, LXXXV, LXXXVIII.
} 
Tampoco hay excesivo cuidado en la definición de las bridas y el atalaje del tiro. En lo que se conserva de mosaico pueden apreciarse las dos riendas que parten de la cintura del auriga hacia cada uno de los iugales, así como la que une a uno de ellos con su vecino inmediato.

\section{II.2. Estudio}

\section{- II.2.1 Las peltas}

Las parejas de peltas son un elemento muy común en la iconografia clásica, no sólo la que se refiere al mosaico, sino también la que afecta a las artes plásticas en general. Algunos paralelos hispánicos los hallamos en Cuevas de Soria, donde contabilizamos hasta tres pavimentos distintos con esta temática y fechados en los últimos decenios del siglo IV ${ }^{5}$. En Mérida aparece en la Avenida de Extremadura, en un pavimento del siglo IV y también en otro el siglo $1{ }^{6}$. En Rielves (Toledo), en Cámara $\mathrm{C}^{7}$. En Las Tamujas de Malpica de Tajo (Toledo) ${ }^{8}$. En Itálica, en un mosaico de Baco de la segunda mitad del siglo $\|$ d.C. ${ }^{9}$. En la villa de Sabinillas de Monilva (Málaga), del siglo $1{ }^{10}{ }^{\circ}$. Como se verá, las cronologías tienden a situarse en época bajoimperial. Pero las peltas son un diseño muy antiguo, de gran pervivencia temporal y geográfica. El siglo । a. C. ya aparecen en Pompeya, en las Casas de Orfeo y de Meleagro ${ }^{11}$. Durante el siglo ॥ se las puede seguir el rastro en todo el Imperio. En este sentido, Fernández-Castro quiere ver en la ocupación de todo el pavimento por parte de las peltas un rasgo que caracterice a las villas tardoimperiales hispanas, por contraposición a lo que sucede en Aquitania, donde funcionan como elemento de relleno ${ }^{12}$ (sería el caso atestiguado entre otros puntos

5 Fernández Castro, M. C., "Mosaicos de la villa romana de Cuevas de Soria" en BlázQuez, J. M. y Ortego, T., Mosaicos romanos de Soria, CME, fase VI. Madrid, CESIC 1983. Mosaicos n. ${ }^{\circ} 55$, págs. 63 y ss. fig. $6, n .^{\circ} 72$, págs. $78, f .21 ;$ y $n .{ }^{\circ} 63$, págs. $71,12$.

s Álvarez Martínez, J. M., Mosaicos romanos de Mérida. Nuevos hallazgos. M.E., 4. Mérida 1990, págs. 93-98, fig. 9, láms. 46-47.

Fernández Castro, M. C., "Mosaicos de Rielves» en Blázquez, J. M., Mosaicos romanos de la Real Academia de la Historia, Ciudad Real, Toledo, Madrid y Cuenca. CME, fase V. Madrid, CSIC, 1982, pág. 72, fig. 23.

3 Blazquez, J. M., Mosaicos romanos de la Real Academia..., pág. 47, láms. 36-37.

9 Blanco Freijeiro, A., Mosaicos romanos de Itálica (I). CME, fasc. II. Madrid, CSIC, 1978.

10 Posac, C., y Rodriguez, P., “La villa romana de Sabinillas (Monilva)». Mainake, 1. 1979, págs 129 y ss. También BLÁzQUEz, J. M. Mosaicos romanos de Córdoba, Jaén y Málaga. CME, fasc. III. Madrid, CSIC, 1981, pág. 99, lám. 77.

BLAKE, M. E., "The pavements of the Roman Buildings of the Republic and Early Empire". MAAR VIII, 1930: 104, lám. 32, 1

'2 Fernandez Castro, M. C., “Mosaicos de la villa romana de Cuevas de Soria», pág. 65. 
en Montmaurín). No es este, sin embargo, el fenómeno que se atestigua en la villa de El Val, donde las peltas son un recurso para rellenar solamente una banda en torno a la composición geométrica principal que se desarrolla por todo el pavimento y rodeando a su vez al emblema.

Por otro lado hay que señalar que las peltas aparecen relacionadas con quadrigas, si bien en una iconografía que representa a una victoria, en un mosaico del Convento de la Merced (Córdoba) fechado en la primera mitad del siglo $1{ }^{13}{ }^{13}$, así como en otro de Mérida, esta vez referido al circo $^{14}$. Las peltas tienen además tradicionalmente un significado profiláctico, en lo que coinciden con los aurigas vencedores, cuya presencia en el arte figurativo es además una llamada a la buena suerte, con lo cual la simbología de unas y otras es perfectamente congruente.

\section{- II.2.2 El campo de meandros de esvásticas y hexágonos}

Este tipo de composición es igualmente muy frecuente en la iconografía de los mosaicos romanos. Los campos de esvásticas pueden envolver distintos tipos de figuras geométricas, como cuadrados ${ }^{15}$ o hexágonos, o aparecer libres de todo tipo de acompañamiento ${ }^{16}$. Su antigüedad les sitúa en la Península Ibérica entre los pavimentos romanos de cronología más alta, como es el de Andión, de finales del siglo ॥ a.C., sobre opus signinum. También en opus signinum hay un ejemplar en Itálica ${ }^{17}$. Sin embargo, viven en la Península Ibérica un cierto florecimiento en época bajoimperial. Los conocemos en Pamplona en el siglo $\mathrm{IV}^{18}$. En Jumilla, a mediados de este mismo siglo ${ }^{19}$. Con una composición muy parecida a la de El Val, aparece en el triclinio de las Cuevas de Soria,

i3 BlázQ'Jez, J. M., Mosaicos romanos de Córdoba, págs. 38 y ss., lám. 24, considera que la figura representada es de un auriga. Pese a su considerable deterioro, parece claro que se trata de una victoria, como aporta LANCHA, J., "L'iconographie du dieu Sol dans la Péninsule Ibérique». Museos, 2, págs. 25-32. Madrid 1983, pág. También Guardia Pons, M., Los mosaicos de la Antigüedad tardia en Hispania. Estudios de lconografia. Barcelona. PPV, 1992, pág. 317 y nota 20.

14 Blanco Freijeiro, A., Mosaicos romanos de Mérida. CME, fase I. Madrid, CSIC, 1977, págs. 155 y ss., lám. 102.

15 Por ejemplo, el de los Quintanares (Soria), en BlázQuez, J. M., y Ortego, T. M., Op. cit., lám. 6.

16 Es el caso del mosaico de la Casa de la Condesa de Lebrija, sobre opus signinum, en Blanco Freijeiro, A. Mosaicos romanos de ltálica, págs. 44, 51 y 52. También en opus signinum en Andión, de finales del siglo I a.C., en MEzQuiriz, M. A., cMateriales procedentes del yacimiento romano de Andión». PV, XXI, 1960. n. 78-79, págs. 57 y ss.; igualmente, BLAzQUEZ, J. M. y Mezouiriz, M. A., Mosaicos romanos de Navarra, CME, fasc. VII. Madrid, CSIC, 1985.

7 Vid supra nota 16 .

- Blázquez, J. M., y Mezouiriz, M. A., Op. cit. pág. 59, fig. 7, lám. 8.

19 Blázouez, J. M., Mosaicos romanos de Sevilla, Granada, Cádiz y Murcia, fase IV. Madrid, CSIC, 1982, pág. 64, f. 22. 
que se fecha en época constantiniana o posterior ${ }^{20}$. En Cabra (Málaga), del siglo III d.C. ${ }^{21}$. En Rielves, de entre 317 y 379 d.C. ${ }^{22}$. En todos estos casos, la figura geométrica compuesta por las esvásticas es el hexágono alargado.

En el resto del Imperio es también un motivo común. Aparece en Thuburbo Majus, en un mosaico conservado in situ y hasta donde nosotros sabemos, inédito. En Bulla Regia ${ }^{23}$, sobre un pavimento de tema circense. En Aldborough. En Saint Colombe ${ }^{24}$, fechado entre los años 175 y 220. Incluso se emplea en ocasiones en bandas que orlan los campos principales del mosaico, como es el caso de Haidra, del siglo iv ${ }^{25}$.

El campo geométrico del mosaico del auriga en El Val está, por tanto, en plena consonancia con un diseño conocido de antaño, y que tiene un cierto éxito en la Meseta durante la primera mitad del siglo iv, como atestigua su presencia en dos conocidos yacimientos, el de Rielves y el de Cuevas de Soria, con el primero de los cuales tiene además nuestra villa otras similitudes de carácter arquitectónico.

Sin embargo, la concepción iconográfica general de nuestro mosaico introduce en los hexágonos una novedad ciertamente original que está en consonancia con la temática circense anunciada por el emblema del auriga. Cuarenta y dos de los sesenta y cuatro hexágonos que se conservan se organizan de la misma forma: un elemento central que recorre longitudinalmente el cartucho y en torno al cual giran diferentes motivos: cables, grecas fraccionadas, foliformes, siempre respetando la idea de deambular en torno a un eje. Si tomamos la representación del circo en la musivaria, tal y como aparece en los mosaicos de Cartago ${ }^{26}$, Gafsa ${ }^{27}$

\footnotetext{
${ }_{21}$ Blanco Freijeiro, A., España romana. Historia de España de Espasa-Calpe, fig. 398. También BlazQuez, J. M. Mosaicos romanos de Córdoba..., pág. 102, fig. 32.

22 Fernández Castro, M. C., "Mosaicos de Rielves", Blazquez, J. M., Mosaicos romanos de la Real Academia de la Historia, págs. 61-75, fig. 36.

23 ENNAIFER, M., "Le théme des chevaus vainqueurs à travers la sèrie de mosaïques Africaines", MEFRA, 95, 1983-82, págs. 817-858.

${ }_{24}$ LANCHA, J., Recueil général des mosaïques de la Gaule, III. Norbannaise, págs. 182 y ss., lám. XCVII.

25 BaRATtE, F., Recherches archéologiques à Haïdra. Miscelanea 1. INAAT, EFR. París-Roma 1974, figs. 2, 4 y 5.

${ }^{26}$ N. 1915 del Museo del Bardo. Sebal, L., y ENNAIFEA, M., "Le gout du cirque en Afrique", en LANDES, CH. (ed.), Cirques et courses de chars. Rome-Byzance. Lattes 1990, fig. 1. EnNAIFER, M., Op. cit., fig. 1. Dunbabin, K. M. D., The mosaics of Roman North Africa. Oxford 1978, págs. 91 y 177

${ }_{27} \quad$ N. ${ }^{\circ} 1888$ del Museo del Bardo. Existe además una amplia bibliografía al respecto. Entre otros pueden consultarse Sebal, L., y EnNalFer, M., Op. cit., pág. 162, fig. 2. YACOUB, M., “A propos d'une mosazïque d'époque vandale en Tunisie". CHAAN, BCTH, 1985, págs. 327-340.
} 25

20 Fernández-Castro, M. A., “Mosaicos de la villa romana de Cuevas...”, págs. 65-67, lám. 


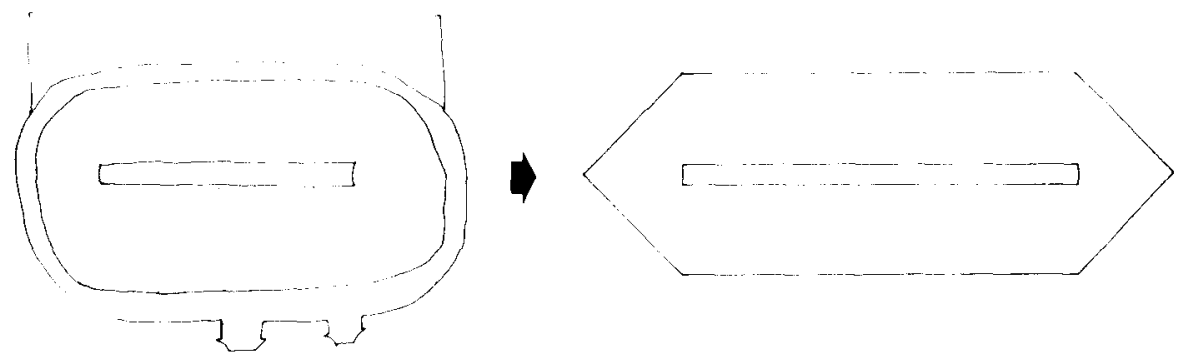

Fig. 12. Geometrización de la planta del circo en un hexágono.

- Volubilis ${ }^{28}$, veremos que su esquematización nos lleva a una arena en forma de rectángulo con los extremos semicirculares, recorrida en dirección longitudinal por una línea recta que indica el euripus o spina. La geometrización de esta forma es un hexágono con dos lados largos, con un elemento central que indica el citado euripus. De esta forma nuestros hexágonos pueden entenderse como una alegoría del espectáculo circense (fig. 12).

En ello incide también la presencia de otros motivos en los restantes cartuchos. Así los delfines que flanquean el emblema se refieren a los contadores de vueltas del circo. El delfín es un animal presente de forma sistemática en la musivaria, así como en la iconografía romana en general ${ }^{29}$, pero en este caso el contexto invita a considerar que su significado concreto es el que se refiere a su uso como contador de vueltas en los ludi circenses. Situadas sobre el euripus del Circus Maximus, las estatuas de siete delfines que vierten agua se combinaban con siete huevos para servir de referencia a corredores y espectadores de cuál es el estado de la carrera en cada momento. Este modelo debió explotarse a los circos provinciales, en la medida en que estos tienden a imitar los modelos propuestos por la arquitectura de Roma, siempre en la medida de sus posibilidades ${ }^{30}$, y puede suponerse que la adopción del sistema de contadores es uno de los usos más baratos y más esenciales, en cuanto a que el euripus, y el contador son referencias visuales asumidas y entendidas por toda la sociedad romana, ya sea itálica, hispánica o de cualquier otro

28 Humphrey, H. J., Roman circuses. Arenas for chariot racings. Londres 1985

29 Para una introducción general al tema, Fennánoez-Galiano, D., Complutum, 1/, págs. 107 yss.

3o Humphrer, M. J., "Le Grand Cirque: Création d'un prototype et sa difussion dans l'Empire", en LANDES, Ch. (ed.), Op. cit,, págs. 44 y ss. También HumphreY, M. J., Roman circuses. 
punto del Imperio. Así lo prueba la abundantísima iconografía que recoge esta función de los delfines, que verterían agua sobre un pilón colocado en el eje axial del circo, como el que se documenta en Leptis Magna ${ }^{31}$. Así, hemos recogido cuatro lucernas: una del Museo Saint Reymond de Tolouse ${ }^{32}$, otra del Museo de Vindonisse, una tercera del British Museum (n. ${ }^{\circ} \mathrm{Q}$ 920) y una última referida por Zangsmeister ${ }^{33}$. En escultura aparecen en un relieve de la villa de Adriano, en un sarcófago de la Sala de la Biga del Vaticano y en otro de la Sala Rotonda de este mismo Museo ${ }^{34}$. En Terracota, una placa del Museo de Arte e Historia de Génova ${ }^{35}$, otra del Louvre ${ }^{36}$ y una tercera del Museo de Viena ${ }^{37}$. Sobre mosaicos, Volubilis, Silin ${ }^{38}$, Gerona ${ }^{39}$ o Lyon ${ }^{40}$. La gliptica y el vidrio ${ }^{41}$ ha proporcionado también representaciones de este tipo que casi de forma sistemática (la mencionada lucerna del Museo de Saint Raymond es una excepción) alude a la iconografía del circo o al menos del euripus completo.

Los hexágonos que contienen cántaros con motivos vegetales tienen una interpretación mucho menos precisa que los delfines. Las cráteras y cántaros se relacionan con la iconografía báquica en cuanto son los contenedores del vino, que es un principio vital, y por tanto tiene un significado benéfico que justifica su presencia en infinidad de mosaicos. Son, por tanto, muy congruentes con la semántica del auriga, vinculado también a la suerte y a los buenos augurios, relacionándose igualmente ccn las peltas. Incluso encontramos cráteras que contienen las palmas trinfales de una carrera de carros en un mosaico de Mokhnine, en Túnez ${ }^{42}$.

Los cántaros de nuestro mosaico acusan un fuerte proceso de esquematización, alejándose de modelos pictóricos que pudieron inspirar de forma directa a los artesanos que facturaron otros mosaicos complutenses

\footnotetext{
Humphrey, M. J., Roman circuses.

LANDES, Ch., Op. cit., pág. 243, fig. 32

HUMPhREY, M. J., Roman circuses. Respectivamente, figs. 90, 89, 88.

Humphrey, M. J., Roman circuses. Respectivamente, figs. 96, 99, 102.

Humphrey, H. J., Roman circuses. Fig. 86.

Humphrey, H. J., Roman circuses... Fig. 83; también Landes, Ch., Op. cit., p. $221, n .{ }^{\circ} 9$.

Humphrev, H. J., Roman circuses... Fig. 81.

B Humphrey, H. J., Roman circuses, respectivamente, figs. 108 y 107.

39 Lanoes, Ch., Op. cit., pl. IV. También Stern, H., Recueil Géneral des mosaiques de la Gaule, II. París 1967, págs. 63 y ss., láms. LXIX.

40 BALIL, A., "Mosaicos circenses de Barcelona y de Gerona”, BRAH, 51. Madrid 1962, págs. 257 y SS. BARRAL I ALteX, X., Les mosaiques romaines et mèdièvales de la Regio Laietania.

${ }^{41}$ Para más datos sobre el tema, véase el catálogo de la exposición de Lattes en LANDES,

${ }_{42}$ Duval, N., "Les prix du cirque dans l'Antiquité tardive", en LANDES, Ch., Op. cit., págs.
} Barcelona 1978. Ch. (ed.), Op. cit. 135-146; fig. 14. 
con esta misma temática, como el de Aquiles ${ }^{43}$. Esto podría indicar una cronología especialmente tardía para el mosaico de El Val, en cuanto a que se supone habría un proceso que culminaría en esta esquematización y que partiría de una representación más realista y más ligada a la pintura, que podría situarse en el siglo III d.C. ${ }^{44}$.

Dada la gran cantidad de pararelos, que se multiplican tanto geográfica como cronológicamente, y que nos llevaría a un ámbito cultural tan distante como el islámico de la Cúpula de Roca de Jerusalén, del siglo $\mathrm{VII}^{45}$, remitiremos solamente a unos pocos de ellos. Entre los más cercanos, los mosaicos, de Aquiles y Baco de Complutum ${ }^{46}$. Muy interesante por relacionarse con la iconografía de la Victoria, que sigue unos esquemas muy parecidos a los aurigas vencedores, y a su vez rodeado por campos de peltas, es el mosaico del Convento de la Merded en Córdoba ${ }^{47}$.

\section{- 11.2.3. El emblema}

El emblema denota una calidad de ejecución muy distinta a la del campo geométrico, donde la sensación de conjunto prevalece sobre el cuidado en el detalle. Por el contrario, los artesanos se han volcado en la pintura de los protagonistas de la escena circense, donde incluso pueden distinguirse dos manos diferentes: la encargada del auriga, en donde se emplea tesela muy pequeña, de $0,5 \mathrm{~cm}$ de lado por un término medio, y que adapta fielmente una sensación pictórica, y la que realiza los caballos y fondos, con tesela algo mayor y una adaptación normalizada de las figuras a esquemas musivos.

Los aurigas vencedores constituyen de hecho un género iconográfico concreto, emparentado con un segundo género que es el de escenas circenses de carácter narrativo. Ambos tipos están presentes en El Val, es más, constituyen el total de la decoración figurada que ha podido recuperarse en la villa sobre cualquiere soporte: el primero en mosaico y el segundo en pintura, aunque de este solamente reste un pequeño fragmento a nivel testimonial. En las siguientes líneas sólo estudiaremos nuestro emblema con el auriga vencedor, dejando para el comentario de la pintura mural (vid infra) todo lo que se refiere a las escenas narrativas.

Sobre el tema se ha escrito mucho, principalmente en referencia a los

${ }_{43}$ El estudio sobre el mosaico de Aquiles contiene también un somero pero preciso comentario sobre la iconografía de las cráteras. Ver FERNANDEZ-GaLIano Ruiz, Complutum II, pág. 69.

44 Vid supra nota 43

45 Grabar. O., La formación del arte islámico.

46 Fernández-Galiano Rúlz, D., Complutum II. Págs. 69 y 168 y ss., figs. 1 y 10, láms. XIV, XVII, XXXIX, XL, XCI Y XCII.

47. Vid supra nota 13 . 
repertorios norteafricanos ${ }^{48}$. Los dos intentos de sistematización a cargo de Dunbabin son imprescindibles para entender la naturaleza y el significado de esta iconografía, comenzando por la propia concepción del diseño, que en el mosaico de El Val se aporta de los esquemas más frecuentes. Los aurigas victoriosos se representan de pie, por lo general sobre una quadriga, portadores de símbolos del triunfo (una palma y en ocasiones una corona metálica) y levantando la mano que maneja el látigo, características éstas que se cumplen en nuestro caso. Sin embargo, la perspectiva elegida para la mayoría de estas representaciones, especialmente cuando el soporte es de tipo musivo, pero también sobre otros materiales, es la frontal, tanto para el carro como para el auriga ${ }^{49}$, mientras que el esquema adaptado en El Val mantiene la frontalidad de éste, pero gira buscando el perfil de aquél (en realidad, los tres cuartos). Emblemata frontales los conocemos en un gran número de mosaicos: El de Eros de Dougga ${ }^{50}$, el de Polydus de Trier ${ }^{51}$, el del Museo Nacional de Arte Romano de Mérida, el también emeritense de la Calle Holguín ${ }^{52}$, el de Moknine ${ }^{53}$, el itálico del MAN de Madrid $^{54}$, y un variado número de ejemplares a los que hay que añadir la iconografía que se refiere al emperador, en diversos cargos públicos o al dios Helios, bien sobre mosaico, como el sectile del cónsul lunius Bassus ${ }^{55}$, bien en escultura, cerámica o incluso tejido, como el peculiar fragmento bizantino de Cluny ${ }^{56}$.

Con respecto a nuestra perspectiva compuesta, pese a no ser la más frecuente la encontramos también en varios mosaicos: así en Thuburbo Majus $^{57}$, en el emblema de la Vía Apia expuesto en el MAN de Madrid ${ }^{58}$ o en un tercero de Sainte Colombe ${ }^{59}$.

${ }^{48}$ Intentos globales de descripción han corrido a cargo de YACOUB, M., Recherches sur les moaíques tunisiennes relatives au monde du cirque. Tesis Doctoral defendia en París en 1979; DUNBABIN, K.M.D., "The victorius charioteer on mosaics and related monuments". AJA, 86, 1982, págs. 65-89; por último, aunque referido más bien al tema del caballo vencedor, el texto ya citado de ENNAIFER.

${ }_{49}$ DUNBABIN. K.M.D., "The victorious charioteer", págs. 70 y ss

5o Dunbabin. K.M.D., The mosaics, pág. 97, pl. 88. EnnalFer, M., Op. cit, pág. 823, nota 3 , fig. 3, Yacoub, M., Le Musée du Bardo. Túnez 1970.

5. DunBaBIN. K.M.D., "The victorious charioteer", págs., pl.

52 Alvarez Martínez, J.M., Op. cit., págs. 79 y ss., figs. 7-8, láms. 39-45.

53 EnNalFer, M., Op. cit., pág. 838, fig. 29.

${ }^{54}$ BlázQuez, J.M., "Mosaicos y pinturas con escenas de circo en los Museos Arqueológicos de Madrid y Mérida" Bellas Artes, 74-75. Madrid 1974, págs. 19-23. También BunBaBIN. K.M.D., "The victorious charioteer", págs. , figs. 11 y 12 para los mosaicos del MAN.

${ }_{55}$ Mural del Palazzo Vecchio de Florencia. Entre otros. HeNING. M. (ED.), El arte romano. Barcelona 1985. Láms. color.

${ }_{56}$ LANDES, Ch.: Op. cit., n. ${ }^{\circ} 73$, págs. 315-318.

57 Duval. N., Op. cit., fig. 10.

${ }_{58}$ Vid Supra nota 54.

59 DUNBABIN, K.M.D., "The victorious charioteer". 
Esta perspectiva se prodiga más en soportes no musivos, y así la encontramos en la Casa de los Aurigas de Ostia, donde se representa en pintura mural a dos bigae en sendos cuadros ${ }^{60}$, así como en una parodia de la Casa de los Vettii, donde los caballos son suplidos por gacelas. También se encuentran en lucernas o contorniatos, casi siempre de cronologías tardías ${ }^{61}$. Sí que aparecen en cambio sobre mosaico cuando se trata de presentar al vencedor dentro de una composición narrativa, como en Gerona, Barcelons ${ }^{62}$ y Piazza Armerina ${ }^{63}$, aunque en este último la frontalidad no es total.

Las características de nuestro auriga tiene unas referencias muy claras a la iconografía bajo imperial, no sólo por la frontalidad, tan de moda en época tardía, sino también por el gesto elegido para el rostro, con los ojos grandes y la mirada fija, hierática y perdida al frente. Son rasgos que se repiten referidos a personajes oficiales (el emperador, los cónsules) o mitológicos (Helios), y que se aplican también cuando se trata de buscar unos resultados parecidos en otros contextos. Con respecto a la frontalidad es muy interesante el desarrollo que de los paralelos iconográficos entre emperador, auriga y Helios hace Dunbabin ${ }^{64}$. Sobre la concepción hierática del rostro, que remite a la majestad y la grandeza, es muy sugerente comparar el auriga de El Val con los tetrarcas de Venecia o con la estatua monumental de Constantino del Museo Capitolino ${ }^{65}$.

Con respecto a la indumentaria del auriga, se trata de la habitual en estas representaciones. El casco es redondo y ceñido al cráneo, con sendas volutas a los costados que se refieren a defensas para la nuca. La chaqueta es de manga larga, como es característico de los cocheros de circo, que se protegen también con pantalones largos y polainas de los traumáticos resultados de los naufragios, donde los desollamientos son seguros en caso de no llevar la adecuada protección, que se complementa con una chaquetilla o lórica de bandas anudadas al frente. Dicha prenda,

60 Calza, G.y Becatti, G., Ostie. Roma 1960, pág. 38. También Barbet, A., "Le goût du cirque dans la pinture murale romaine", en LANDES. Att. Op. cit., págs. 91-97, pág. 92, figs. 1 y 2.

61 DunbabiN, K.M.D., "The victorious charioteer", págs. 67-68

62 Vid supra nota 40.

63 Sobre los mosaicos de Piazza Armerina, se puede consultar una copiosa bibliografía. Así, Dunbabin. K.M.D., "The mosaics", pág. 203 y ss. Carandini, A.; Ricci, A. y De Vos, M.: Filosofiana, the villa of Piazza Armerina. Palermo 1982; SETtis. S., "Neve forschungen und untersunchungen zur villa von Piazza Armerina", en Palast und Jütte, Deiträge zur baven un whomen im Altertum. Majencia 1982, págs. 525-534. LANDES, Ch., Op. cit.

64 Vid supra nota 49.

55 Sobre estos aspectos puede verse REECE, R., "El arte en la Antigüedad tardía”, en HENING, M., Op. cit. págs. 275-292, págs. 275 y ss.; también BARral I Altex. X., Antigüedad Clásica. Vol. II de la Historia del Arte. Barcelona, Ed. Planeta, 1989. 
que recuerda poderosamente a la tipología de la militar lórica segmenta$d a^{66}$, es de un material fuerte, pero elástico, probablemente cuero.

El conjunto lo complementa un ancho cinturón y un faldellín de ptereuges, elemento también de clara inspiración militar clásica que conocemos desde los ejércitos de hoplitas, y que cronológicamente tiene una referencia más cercana es el equipo bajoimperial de los oficiales romanos ${ }^{67}$.

Paralelos para la indumentaria los hay en los mosaicos citados más arriba, a los que añadiremos el del auriga a pie de Dougga ${ }^{68}$, que además tiene un extraordinario parecido con el de El Val, y el repertorio de personal circense del mosaico de los Caballos de Cartago ${ }^{69}$. Lo más atípico es la presencia de ptereuges, que no hemos podido identificar con claridad en relación con cocheros en la iconografía musiva, aunque cabe la posibilidad de tal interpretación en el mosaico de Eros de Dougga ${ }^{70}$. Además uno de los participantes en la carrera representada en el mosaico de Gerona ${ }^{71}$ parece llevar un faldellín de cuero, y la propia naturaleza del espectáculo tiene una gran congruencia con su uso.

Respecto al engalanamiento de los caballos, con una pequeña palma sobre la frente y un penacho sujeto a la brida, se documenta total 0 parcialmente en las representaciones que ya hemos citado. Añadiremos los mosaicos de la Casa de Sorothus de Susa, donde además los caballos son los únicos protagonistas de las distintas escenas ${ }^{72}$.

El símbolo de triunfo que presenta el auriga de El Val es el más común, la palma que constituye el premio de los vencedores según una antiquí-

${ }^{66}$ La lórica segmentada tiene una perduración que se mueve entre finales de la época julioclaudia y un momento de dificil precisión a finales del siglo II d.c. Tiene una amplia presencia en la iconografía (el ejemplo más representativo es la Columna de Trajano de Roma) y en la bibliografía al uso: así RoBINSON. H.R., The armour of Imperial Rome. Londres 1975: WEBSTER. G. The Roman Imperial Army of the first and second centuries a.d. Londres 1969

${ }^{67}$ Apenas hay bibliografía especializada sobre los ejércitos bajoimperiales. Puede consultarse a nivel general HACKETT. J. (ed.): Warfare in the ancient world. Londres 1989. De nuevo los tetrarcas de Venecia son un buen paralelo.

${ }_{68}$ Museo del Bardo, n. ${ }^{\circ}$ inv. 2749. Yacoub. M., Le Musèe du Bardo. Merlin y Poinssot, L., "Factions du cirque et saisons sur des mosaiques de Tunisie", MP, 2 1949, págs, 739-742, fig.

1. Dunbabin. K.M.D., "The victorious charioteer", págs. 69 , fig. 6.

69 Salomonson. J. W. Mosaique aux chevaux de l'antiquarium de Carthage. Le Haye 1965; Ennaifer, M., Op. cit., págs. 825, figs. 6 y 7; Dunbabin, K.M.D., The mosaics, págs. 95-96, láms. 84-85.

Vid. supra nota 50

Vid supra nota 40.

72 Foucher, L., Inventaire des mosaïques. feuille n. 57 de l'Atlas Archèologique. Sousse. Túnez, INNAT. 1960, págs. 58-59, pl. xxVII y xxx।. 
sima tradición clásica que se remonta hasta en torno al año 400 a.C. ${ }^{73}$.

Y llegamos por fin al punto más problemático dentro del estudio de la iconografía de los aurigas, la interpretación de la simbologia que encierran. Dunbabin desarrolla un extenso trabajo sobre este punto, considerando que en general se trata de símbolos de buen augurio, aunque contempla también la existencia de emblemata de tipo conmemorativo.

Los mosaicos de tipo conmemorativo pueden identificarse como tales con cierta seguridad cuando figura el nombre del auriga y/o de los caballos. Este dato falta en el de El Val, no sabemos si porque nunca existió o porque se ha perdido con el resto del emblema. Lo que sí se reconoce con facilidad es su vinculación con una facción concreta, la de los verdes. Con respecto a los aurigas y motivos circenses en general y de modo más específico con todos aquellos que no aparecen identificados con sus nombres propios, las propuestas de interpretación se alejan del significado conmemorativo para acercarse al simbólico. El circo tiene unas fuertes connotaciones cosmológicas ${ }^{74}$ que han llevado muchas veces a explicar la presencia de los aurigas en el arte romano como elemento mitológico. Es difícil comprobarlo con visos de certeza en la mayoría de los casos, pero sí es cierto que los aurigas vencedores conllevan siempre un significado benéfico, ya que con la invocación a su triunfo y buena fortuna el posesor del mosaico pide también por su buena fortuna personal, empleándolo a la vez como símbolo de victoria y de buen augurio, idea ésta que en el emblema de El Val se ve reforzado por las plantas que rodean al círculo central, como es frecuente en la iconografía al uso. Es cierto que el arte romano tiene una fuerte carga simbólica, e igualmente la tienen los cocheros vencedores, especialmente cuando no hay datos (como inscripciones, aunque éstas también deben ser manejadas con precaución) que permitan identificarlos en un sentido claramente conmemorativo. Sin embargo, el contexto arqueológico que envuelve el mosaico de El Val (la existencia de pinturas murales de tema circense, la identificación de una serie de recintos como establos o la misma ubicación geográfica de la villa) invita a pensar en una doble lectura, donde el significado simbólico y benéfico se una con una referencia real al mundo de las carreras de carros, el circo y los caballos.

73 Tarbell, F.B., "The paim of vitory". Classical Philology, III. Chicago, 1908, págs. 264-272. El premio de los aurigas se complementaría con una corona agonística metálica. Ver también Duval, N., Op. cit. También Ripoll, G., "Panem et circenses". Espacio, Tiempo y Forma, serie 1-3. Madrid 1990, págs. 305-320, págs. 319.

${ }^{74}$ WILleumier, “Cique et Astrologie». Mefra, Xlıv, 1927, págs. 184-209; Dunbabin. K.M.D., The mosaics, págs. 88-89; MERLIN. A. y Poinssot. L., Op. cit.; este último trabajo sobre las alusiones al ciclo natural de las estaciones que está implícito en las facciones y el espectáculo circense. 
Sólo de esta forma se explica la insistencia en el tema ecuestre, que se repite en pinturas murales en otros ambientes de nuestro yacimiento, como veremos más adelante.

\section{- II.2.4. Cronología}

La cronología de estas representaciones nos lleva al Bajo Imperio. Dunbabin considera al auriga vencedor en posición frontal un producto tardío, posterior a las escenas narrativas de carreras de carros, y que se fecharía a finales del siglo 111 o en el siglo iv ${ }^{75}$. La pervivencia es muy larga, pues como hemos visto esta iconografía aún se encuentra en los siglos VIII-IX en Bizancio. Pero por otro lado hemos de advertir de la constatación arqueológica de aurigas victoriosos en diversos soportes y de fecha anterior, y la misma perspectiva compuesta con el auriga frontal y los caballos de perfil (o mejor en tres cuartos) tiene una aparición bastante antigua en la Casa de los Vetti, aunque después sólo lo encontremos de finales del siglo ॥ d.C. en adelante ${ }^{76}$. El desarrollo de la iconografía parece haber tenido lugar el siglo $\mathrm{I}$, y en dicha centuria se fechan casi todos los mosaicos de esta temática: el de la Casa de los Caballos de Cartago, el 330 d.C. ${ }^{77}$. El del auriga a pie de Dougga, muy parecido al nuestro tanto por el auriga como por la vegetación benéfica, en la segunda mitad del siglo $\mathrm{IV}^{78}$. El de Eros de Dougga, en el siglo $\mathrm{IV}^{79}$. Los de Piazza Armerina en el siglo IV (¿quizás entre 320 y 330 d.C?) ${ }^{80}$. Los de Mérida, en el siglo $\mathrm{IV}^{81}$, así como las pinturas murales de la Calle Suárez Somonte, de la primera mitad de dicha centuria ${ }^{82}$. $Y$ ya hemos visto cómo el ejemplaar más antiguo de auriga de frente y quadriga de perfil sobre mosaico es en todo caso el de Sainte Colombe, de finales del siglo III o principios del iv d.C., así como los contactos de nuestro auriga con diversas representaciones de época tetrárquica. Por último, se detecta una importante época para los juegos de circo en los primeros años del siglo IV d.C., época en la que Humphrey ha detectado la construcción de cinco circos y la remodelación de otros varios en toda la geografía imperial ${ }^{83}$. Estas constantes referencias a la tetrarquía son por fortuna muy congruentes con los datos proporcionados por la excavación arqueológica, que nos

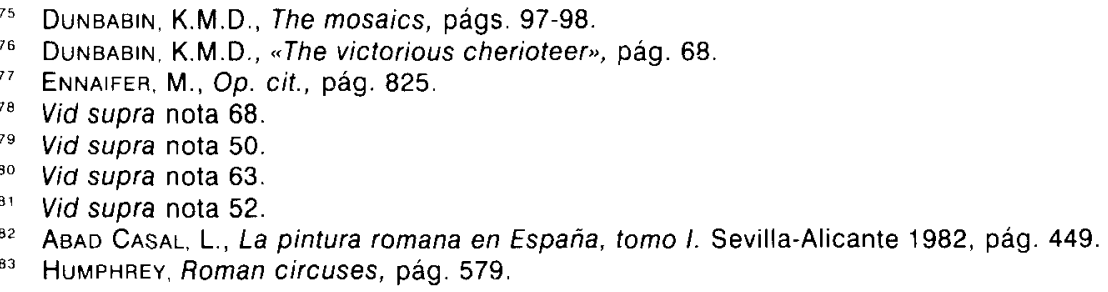


ha llevado a fechar la villa en el último cuarto del siglo III d.C., lo que nos lleva a considerar para el mosaico una fecha entre los últimos años del siglo III y principios del IV d.C.

- I1.2.5. Algunas consideraciones técnicas sobre la ejecución del mosaico del Auriga

El propio estudio del mosaico nos ha llevado a concluir que existen como mínimo dos manos (o dos talleres) en la ejecución del mismo. Una vez arrancado, la contemplación del rudus certifica esta idea, pues su mortero ha fraguado en dos momentos diferentes y huella de su unión indica que el emblema se instaló en un momento distinto del campo geométrico. Además a raíz de la extracción de aquél se recuperaron algunos fragmentos de madera, que pertenecerían al soporte sobre el que se teseló o simplemente sobre el que se trasladó, lo que nos hace pensar que el proceso de construcción fue el siguiente:

1. Un grupo de artesanos de un taller concreto manufacturan in situ todo el campo geométrico, dejando el hueco preciso para la instalación posterior del emblema central.

2. Se instala el emblema, que ya ha sido realizado en las dependencias de un taller musivario y luego trasladado a la villa, como parece que habría que deducir de la presencia de fragmentos de madera en el mortero de su rudus. En su confección intervino probablemente el maestro musivario, probablemente el mismo personaje que dibujó o adaptó los cartones, y quizás algún artesano más para rellenar fondos y desarrollar los caballos y el carro.

Esta hipótesis explicaría además las diferencias de calidad que se advierten entre el campo geométrico y el emblema, y dentro de éste entre el cochero y los caballos.

En la misma ciudad de Complutum hemos advertido esta coexistencia de dos partes claramente diferenciadas en un mismo mosaico en el musivario Hippolytus, recientemente excavado ${ }^{84}$.

Hay un punto que no puede esclarecerse: si el taller que realizó el emblema es el mismo que hizo el campo geométrico, o si por el contrario se trata de uno distinto, así como la atribución geográfica de ambos, aunque parece lógico pensar en un equipo complutense al menos para

84 Rascón Marques S.; Polo lópez J.; Méndez Madariaga, A. y Gómez Pallares J., "Hipopolytus: estudio de un nuevo mosaico de género de pesca y con inscripción procedente de Complutum». Lucentum (en prensa). 
la ejecución del segundo. Desde luego no hay criterios que nos permitan suponer un origen africano para los autores del emblema, cosa que en cambio sí ocurre con el ya citado mosaico de Hippolytus, donde en un motivo típico del Norte de África se une el uso de materiales tunecinos.

\section{OTROS DATOS ARQUEOLÓGICOS REFERENTES AL MUNDO DE LAS CARRERAS DE CABALLOS EN LA VILLA DE EL VAL}

\section{III.1. Pintura mural}

\section{III.1.1. Descripción (figs. 13 y 14)}

El fragmento de pintura mural que aquí se publica pertenece a la villa de El Val, pero su procedencia exacta es sólo conjeturable. Se recogió en 1970 durante las obras de extracción de grava que motivaron la pérdida irremediable de gran parte del yacimiento. Contamos con testimonios verbales de Fernando Garcés Toledano y José Garcia Saldaña, miembros del grupo arqueológico local que participó en las tareas de salvamento, quienes han situado el hallazgo en la zona sur de la villa, en un punto que podría corresponderse con la habitación absidada que en alguna ocasión hemos querido interpretar como un triclinium ${ }^{85}$ (fig. 2). En estos últimos veinte años, este interesante fragmento ha sido publicado varias veces ${ }^{86}$.

La pintura representa a un auriga que conduce una biga lanzada al galope en el curso de una carrera. Sólo conservamos al conductor y a los dos caballos, habiendo desaparecido casi por completo el carro. El auriga viste una túnica de mangas largas y rojas. El rostro se soluciona con un degradado de colores que protagonizan los brillos de nariz, labios y carrillos. Sobre la cabeza, un tocado que no se distingue adecuadamente pero que debe interpretarse como un casco. Sus manos gobiernan a los caballos por medio de cuatro riendas (una para cada freno), mientras que la derecha empuña el látigo, todavía fuera de uso. Los caballos, de color castaño y con las palmas sobre la frente, galopan mirando a la pista que se extiende ante ellos.

as Méndez Madariaga, A. y Rascón Marques, S., "La villa romana de El Val”, pág. 55.

86 Castellote Herrero, A. y Garcés Toledano, F.; Op. cit. Méndez Madariaga, A. y Rascón Maroues, S., "La villa romana de El Val", pág. 54. También es objeto de una comunicación inédita de LucAs Pellicer, M.R., en las I Jornadas de Pintura Mural Romana en Hispania, celebradas en Valencia en 1989. 


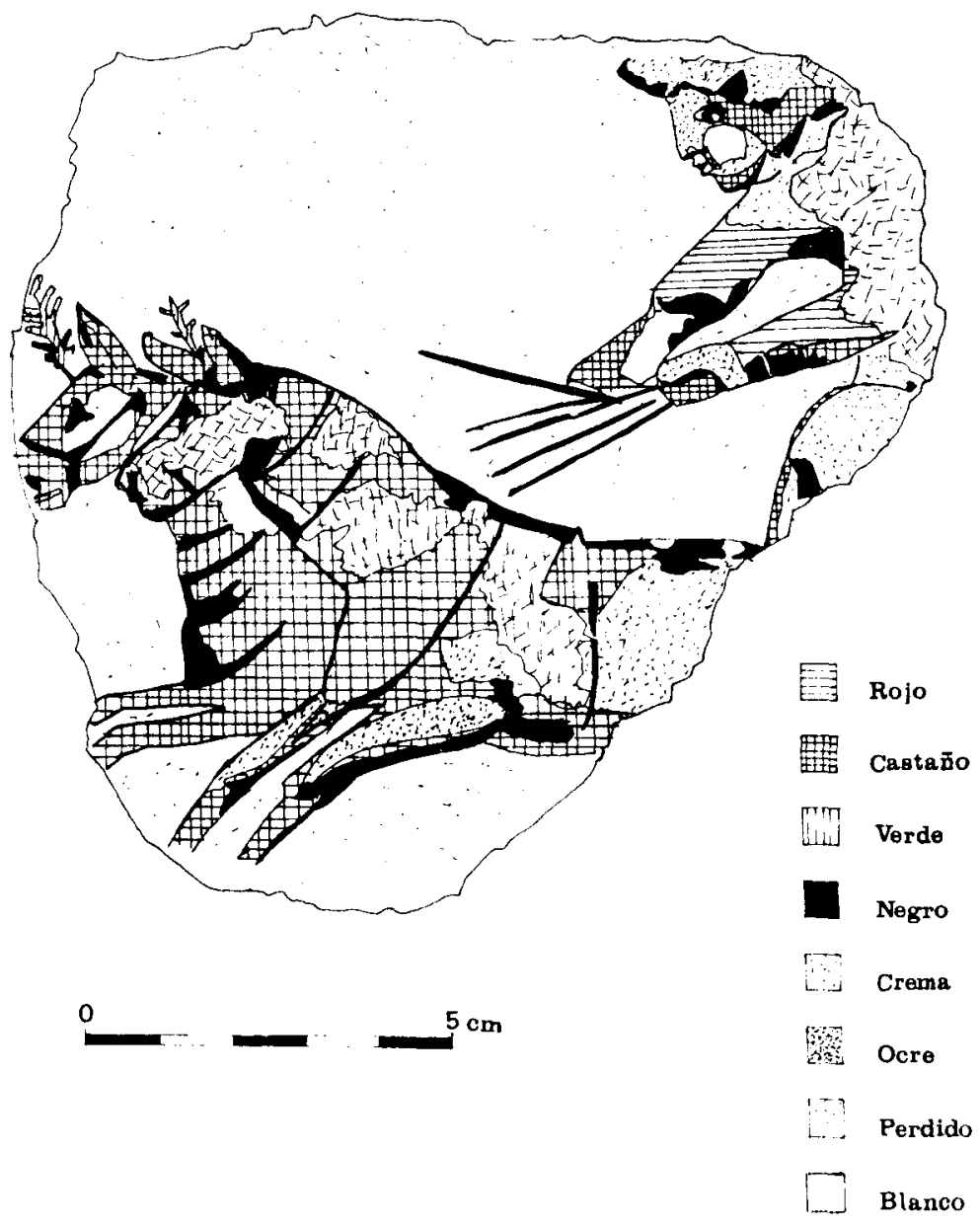

Fig. 13. Pintura mural con decoración de una biga.

La pintura está realizada a la encáustica, al igual que todas las recuperadas en la villa de El Val ${ }^{87}$.

87 El análisis de las pinturas de la villa de $\mathrm{El} \mathrm{Val,} \mathrm{al} \mathrm{igual} \mathrm{que} \mathrm{las} \mathrm{de} \mathrm{Complutum} \mathrm{y} \mathrm{una} \mathrm{serie}$ más amplia de otros yacimientos romanos peninsulares y extrapeninsulares, ha sido efectuado por Jorge y Joé Cuní, a quienes agradecemos estos datos. Sobre el particular, véase CuNI, J. y CUNI, J. «Roman mural paintines techiques in Merida» (en prensa). 


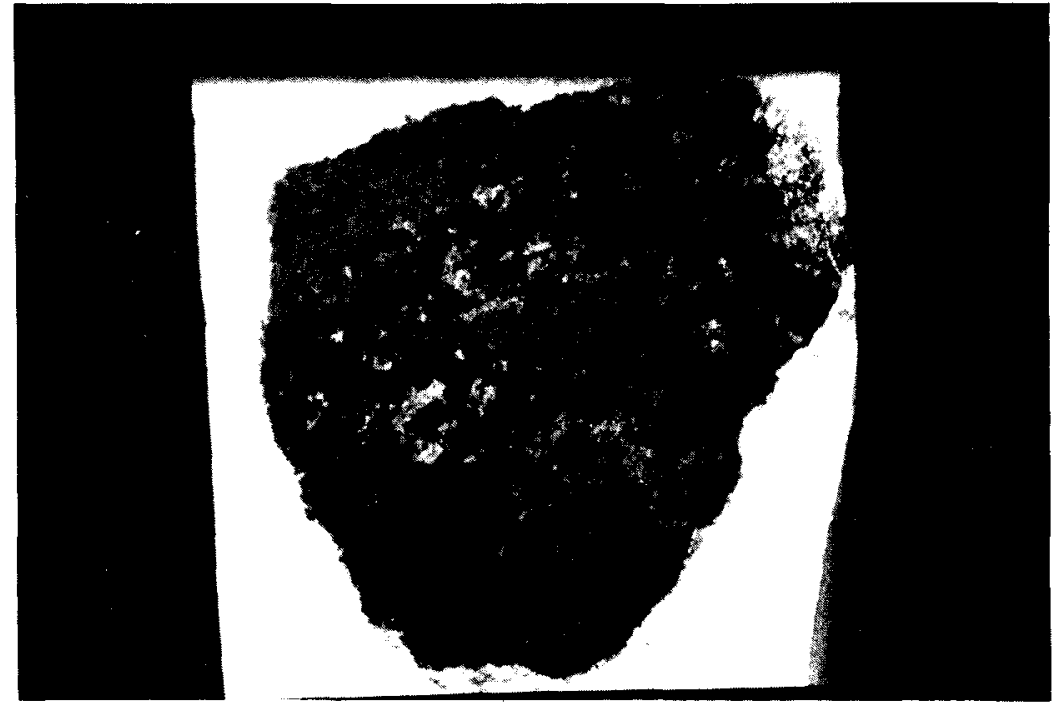

Fig. 14. Fragmento de pintura mural con decoración de una biga.

\section{III.1.2. Estudio}

Al igual que el mosaico del oecus, nuestro fragmento de pintura mural alude a una escena de los Ludi Circenses. En dos aspectos se diferencia de aquél: por un lado, no entra en el subgénero de aurigas y vencedores, sino en la categoría narrativa. Por otro, no se trata de una cuadriga sino de una biga. Se ha propuesto en ocasiones que las escenas narrativas conmemoren acontecimientos reales y concretos, significando su presencia en una vivienda el recuerdo de juegos patrocinados por el propietario $u$ otra actuación de éste con respecto al evento evocado por el emble$m a^{88}$.

La representación, con las carreras en pleno apogeo, es un motivo iconográfico habitual dentro del género de las escenas circenses. Se trata de diseños llenos de acción que tienen un fuerte interés documental, ya que los artistas acostumbran a representar a todos los personajes que intervienen en el transcurso del espectáculo. Por lo general, aparece incluso la representación con todo lujo de detalles de la arquitectura que

es DUNBABIN, K.M.D., "The victorious charioteer", pág. 82, propone esta interpretación para escenas especialmente complejas como las de Piazza Armerina, Gerona o Barcelona. 
envuelve a los cocheros y los caballos: el circo y sobre todo el euripus o spina y las carceres. Dichas representaciones han llegado hasta nosotros ejecutadas con las técnicas más diversas.

En pintura mural contamos con un magnífico paralelo en la carrera de bigae representada en la villa de Pully (Suiza), de mediados del siglo । d.C. ${ }^{89}$. Sin embargo es el mosaico el que nos ha deparado un mayor número de ejemplares. Así ocurre con el de Gafsa (Túnez), del siglo vi ${ }^{90}$; el clásico de Cartago del siglo iv según Sebai y Ennaifer o de fines del ॥ o principios del III según Dunbabin y Picard, que tanto unos como otros consideran prototipo de su serie, y en el que Dunbabin se apoya para defender la existencia de una escuela africana especializada en el tema circense narrativo ${ }^{91}$ el de Piazza Armerina, entre 310 y 300 d.C. según esta misma autora ${ }^{92}$, el de Lyon, de época severiana ${ }^{93}$, el de Gerona y el de Barcelona, del siglo IV ${ }^{94}$, los dos del Cortijo de Paterna (Sevilla) del siglo IV ${ }^{95}$ o el desaparecido del Circo, de Itálica de finales del siglo III o principios del IV ${ }^{96}$. Todos ellos se refieren a carreras de quadrigae. También en mosaico y con bigae, se encuentra el mosaico del Museo Dènon, de Châlon-sur-Saône, del siglo $11^{97}$. A esto pueden añadirse otras representaciones de carácter escultórico, en piedra o incluso en terracotas y cerámicas. Entre las primeras hay que señalar la carrera de bigae de Narbona, de los siglos $\|$ o III d.C., el relieve de Lyon, también de bigae y de una cronología semejante ${ }^{98}$ y sobre todo el magnífico relieve de Foligno, que representa una carrera en el Circo Máximo y que se encuentra en el British Museum ${ }^{99}$. Los ejemplos pueden ser muchos más, pero nos circunscribimos a los mencionados.

89 Fuchs, M., "Courses dans l'hemicycle". Landres, CH. (ed). Op. cit., págs. 99-108.

90 N. 1.915 del Museo del Bardo, Sebal, L. y EnNaIfer, M., "Le goût du cirque en Afrique». Landes Ch., ed. op. cit., fig. 2, pág. 162; YACOUB, M., «A propos d'une mosaíque d'époque vandale en Tunisie", CHAAN, 1985, págs. 327-340.

${ }_{11}$ N."1.915 del Museo del Bardo, Sebal, L. y Ennalfer, M., op. cit., fig. 1; Ennalfer, M., op. cit. fig. 1; DUNBABIN, K.M.D.; "The Mosaics", pág. 91, pl. 177

92 Dunbakin, K.M.D., "The mosaics", pág. 243 y ss., pl. 203.

93 Vid supra nota 39.

94 Vid supra nota 39.

95 BlázQUez, J.M., Mosaicos romanos de Sevilla, Granada, Cádiz y Murcia. CME, fase IV Madrid, CSIC, 1982, págs. 19 y ss. láms. 3 y 40.

96 Blanco Freijeiro, A., Mosaicos romanos de itálica (1). CME, fase II. Madrid, CSIS, 1978.

97 Stern, H. y Blanchard Lemee, M., Recueil général des mosaïques de la Gaule, II. París 1975, págs. 110-111, p| LIX-LX. LANDES, Ch., op. cit., pág. 353. DESBAT, A., "Les représentations du cirque dans les cerámiques". LANDES, Ch., op. cit., págs. 77-80, fig. 2.

98 LANDES, Ch., Op. cit., págs. 326-327, lám. 81.

99 LANDES, Ch., Op. cit., números $79 \mathrm{a}-791$. 


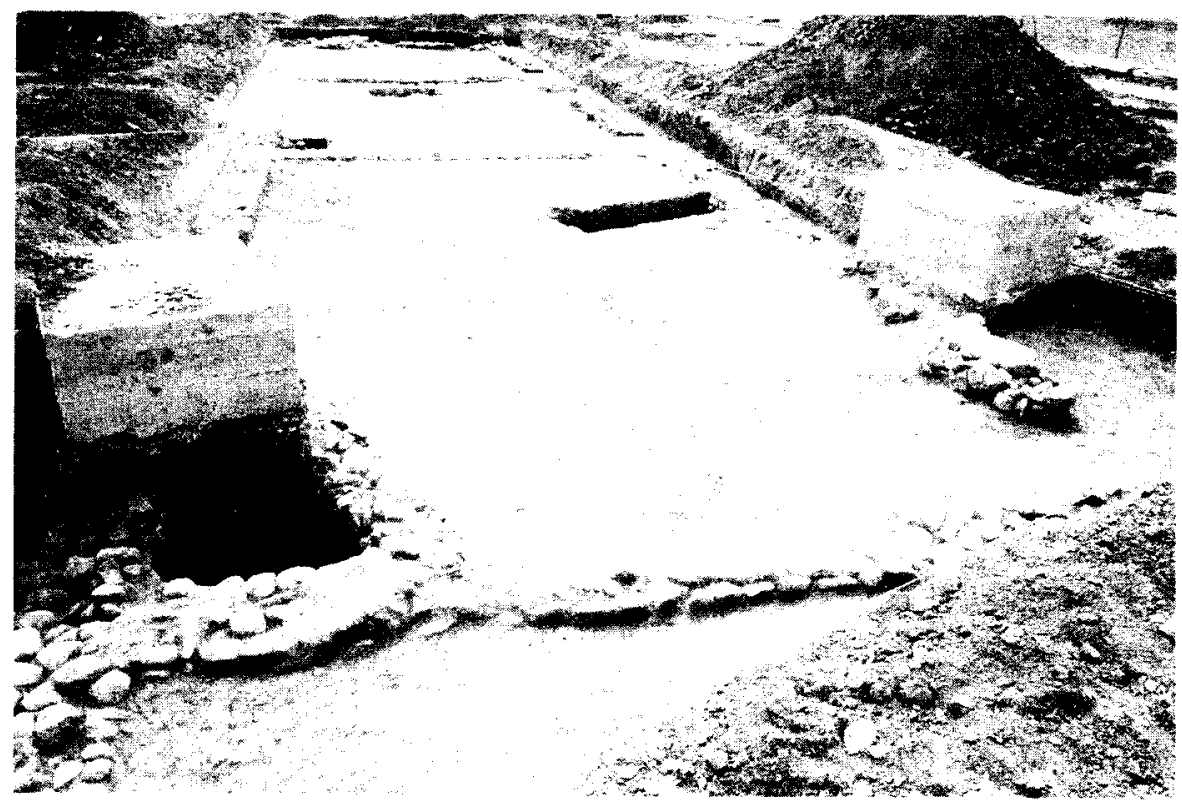

Fig. 15. Las estructuras del Sector F.

Con respecto a las bigaes, éstas se hallaban presentes de forma sistemática en los programas circenses de los grandes juegos romanos junto a las quadrigae y los "desultores», acróbatas que evolucionaban sobre parajes de caballos. Hubo también carros de más caballos, como atestiguan ciertos datos arqueológicos (por ejemplo el entalle que representa a un auriga que conduce un tiro de veinte ${ }^{100} \mathrm{o}$ el tiro de diez en una terracota de Ostia ${ }^{101}$, pero lo habitual eran las competiciones de dos o de cuatro, como dice un texto de Suetonio (César, 39, 4): quadrigas bigasque et equos desultorios agitaverunt nobilissimi iuvenes ${ }^{102}$. Sin embargo la "prueba reina", aquella que requiere mayor destreza y experiencia, debió ser la carrera de quadrigae, con lo que se relaciona con mayor frecuencia la iconografía del auriga triunfante. Es por otro lado evidente

100 VELJOVIC, E. "Le cirque et les courses de Chars dans la glyptique». LANDERS Ch., op. cit., págs. 73-76, fig. 2 .

101 HUMPHREY, J.H., Op. cit., fig. 124.

102 Sobre los programas de los "Ludi Magni" y los juegos públicos en general, ver THUILLIER, J.P., "Le programme hipique des jeux romaines: une curicuse absence», REL, 65, 1987. Paris 1989, págs. 53-73. 
que la dificultad de guiar el carro en torno a la spina, sorteando a los adversarios unas veces y hostigándolos otras, aumenta con el número de caballos que componen el tiro. Así, podemos conjeturar que aún estando las bigae presentes de modo sistemático en las jornadas circenses, el puesto de honor seria para las quadrigae, que enfrentarían a los cocheros y caballos más en forma.

Resulta difícil de adjudicar una cronología al fragmento de pintura mural de El Val, pues como hemos visto alude a un tema que existe desde el siglo I d.C., pero después se prolonga hasta el siglo vi. Parece congruente sin embargo fecharlo con relación a la segunda fase de la villa y por tanto con una cronología equiparable a la del mosaico del oecus. Se ha querido en algunos casos determinados como las complejas escenas de Gerona, Barcelona o Piazza Armerina, relacionar las escenas narrativas con espectáculos concretos que habrian sido organizados por el promotor de dichas obras. Este punto es difícilmente esclarecible en El Val, donde contamos con un mínimo fragmento de la obra original. Pero sí que nos pronunciamos a favor de un significado conmemorativo y desde luego de una relación con una actividad circense real, sobre todo en base a la conjunción con el mosaico del oecus.

\subsection{Las estructuras del sector $F$}

\section{III.2.1. Descripción (figs. 15 y 16)}

El sector $F$ dista ciento cincuenta metros de la fachada Norte de la villa. Se excavó un área de $20 \times 5,20 \mathrm{~m}$, que se complementó con una serie de zanjas y catas de $1,5 \times 1,5 \mathrm{~m}$, que tenían por misión corroborar si las estructuras documentadas se prolongaban hacia el Norte o hacia el Sur. Éstas consisten en un camino de dirección NE-SO que discurre ante una serie de habitaciones alineadas la una junto a la otra, separadas sólo por un tabique divisorio y ofreciendo sus entradas al citado camino.

\section{III.2.1.1. El camino}

El camino tiene un ancho máximo de cinco metros. En su superficie conserva las huellas de los carros, y la ejecución de un corte estratigráfico transversal nos ha permitido comprobar que se ejecutó con dos niveles de distinta obra: un rudus de cantos cuarcíticos sobre el que se superpone una capa de grava compactada por un mortero muy degradado de cal y arena. La potencia máxima de la obra es de $1 \mathrm{~m}$. 


\section{III.2.1.2. Los edificios}

Los edificios se alinean en una larga hilera que discurre paralela al camino, a oriente de este. Están adosados, separados tan sólo por un tabique los unos de los otros. Sus dimensiones son las siguientes:

Ambiente F1: $3,50 \times 6,10 \mathrm{~m}$.
Ambiente F2: $3,50 \times 5,20 \mathrm{~m}$.
Ambiente F3: $3,50 \times 5 \mathrm{~m}$.

Lo único que se conserva es un zócalo de cantos cuarcíticos, de 0,55 $\mathrm{m}$ de grosor y $0,20 \mathrm{~m}$ de potencia. Para la instalación del zócalo sólo se practicó una zanja de cimentación, pero previamente no hubo ningún aterrazamiento, al contrario de lo que ocurrió en el sector $D$. Las puertas se abren al camino, ubicadas siempre en el ángulo NO de cada ambiente, y de una anchura de $0,70 \mathrm{~m}$. El interior de los ambientes es totalmente diáfano, con la salvedad de unas estructuras del mismo tipo de obra que los muros y que se sitúan siempre en la esquina NE, con forma de cuarto de círculo. No se distingue ningún solado, por lo que se supone que el firme sería de tierra.

Pese a haber excavado en tres ambientes, se documentan un número mínimo de siete.

\section{III.2.2. Interpretación}

La relación con las estructuras excavadas en la parte noble de la villa, principalmente las que se intervinieron en las campañas de 1991, así como con el hipotético trazado de la vía que une Complutum y Caesaraugusta, nos sugieren la interpretación del camino como un ramal de servicio que permitiese el acceso al edificio desde la vía principal, situada al Norte.

Con respecto a las estructuras, no cabe duda de su estricto sentido funcional: ofreciendo sus puertas al camino, alineadas sin más a un lado de éste, diáfanas y sin una preparación especial para sus suelos, son espacios ideales como almacenes o establos. La segunda posibilidad se impone sobre la primera si consideramos además la existencia de un pequeño depósito en cada ambiente, depósito que sólo se entiende como un pesebre para los animales estabulados.

Así ocurre en Settefinestre, donde unas estructuras muy parecidas, sólo que alineadas no a lo largo de un camino sino en torno a un patio, y de 


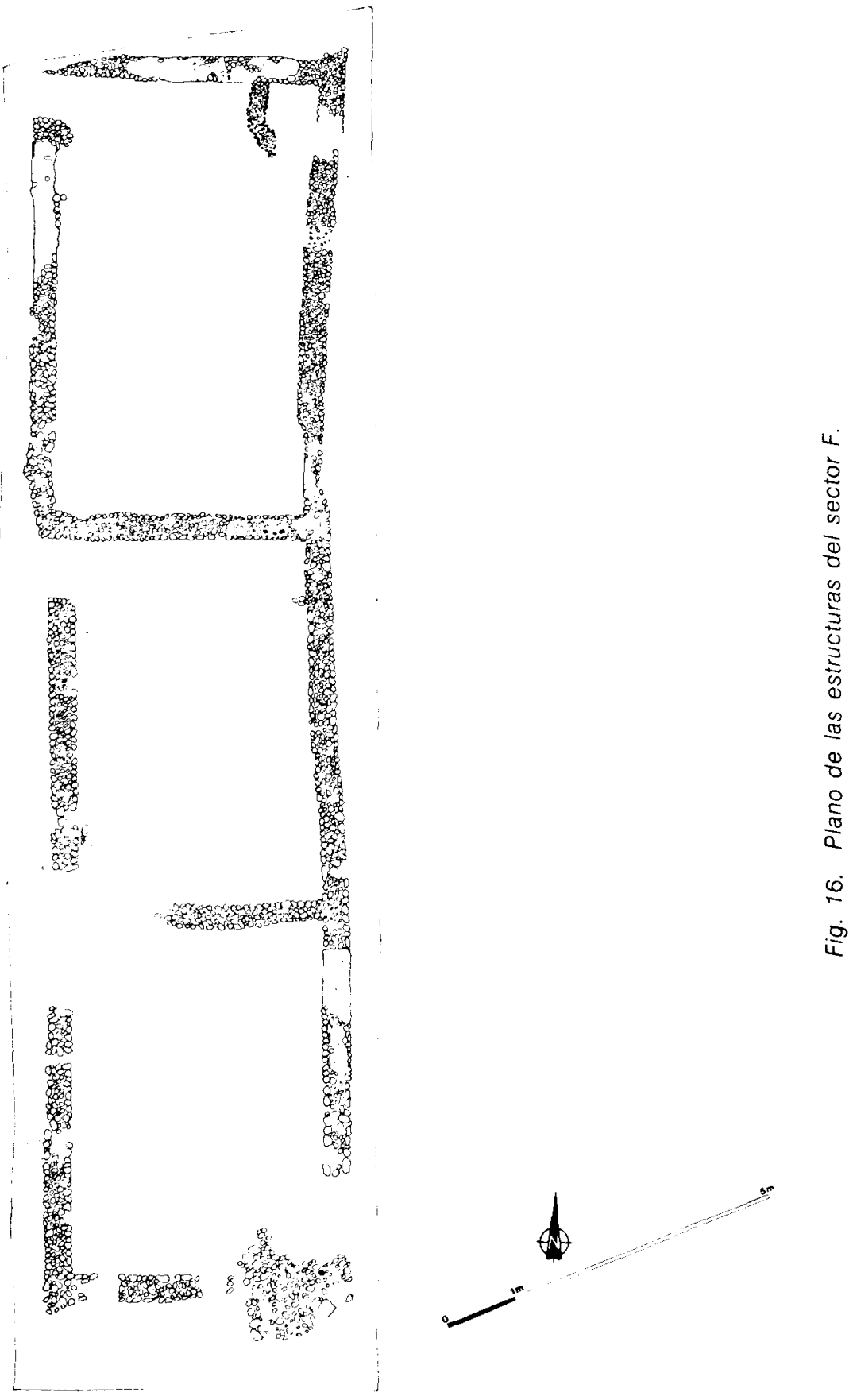


menores dimensiones, se interpretan como porquerizas ${ }^{103}$. La misma Complutum nos ha proporcionado un recinto muy parecido, que aunque de dimensiones algo menores responde al mismo esquema de ambientes diáfanos sucesivos aislados por un único tabique los unos de los otros. Significativamente, no se encuentra en el interior de la ciudad y dentro de su retícula urbana, sino en el exterior y muy próximo al punto por donde accedería la vía que viene desde Emerita Augusta ${ }^{104}$.

Los establecimientos de tipo ganadero son muy poco conocidos en el mundo romano, y por tanto resulta difícil afinar más en nuestro intento de interpretación del sector $F$ de El Val. La iconografía de la villa nos conduce de forma ineludible a plantear la hipótesis de que nuestros establos sean cuadras.

La infraestructura precisa para la cría o el simple uso de caballerías está muy poco documentada en el mundo romano. Sin embargo existen algunos ejemplos a los que se puede recurrir, como el de Oued Athmenia (Argelia), donde un gran corredor diáfano se interpretó como un gran establo ${ }^{105}$. Los campamentos de limes nos han proporcionado también buenos elementos de comparación. Edificios largos y estrechos sin tabiques internos, o barracones combinados con establos de tamaño variable ante los que discurre una calle, camino o paseo, y que oscilan entre los cuatro metros cuadrados y los $3,5 \times 4 \mathrm{~m}$, los hay en Gelduba, Dormagen y Oberstimm. Por fin, una visita a las caballerías que se encuentran en uso hoy por hoy ${ }^{106}$ nos remite de nuevo a los mismos elementos estructurales: un edificio alargado, a veces con algunos tabiques divisorios internos, ante el que corre un camino o un paseo cuando no se encuentra flanqueado un patio central.

Por otra parte, estructuras como las del sector $F$ son susceptibles, por el mismo hecho de ser tan claramente funcionales, de emplearse para estabular otro tipo de ganado que también se documenta en la villa como

i03 CARANDINI, A. Settefinestre. Una villa eschiavistica nella Etruria romana, II. La villa nell sui parti. Módena, Ed. Panini, 1985, págs. 182 y ss.

104 Méndez Madariaga, A y Rascón Maroues, S., Complutum II!: La ciudad y los edificios públicos (en prensa).

to5 Berthief, A., "Etablissements agricoles antiques a Oved-Athménia». BAA, I, 1962-65. París 1967

:06 En esta línea es ilustrativa una visita al complejo del hipódromo de la Zarzuela de Madrid No queremos dejar de agradecer aquí su colaboración a un veterano cronista hípico experto en el tema, como es Sebastián Rascón Garcia. Igualmente, remitimos al interesado al estudio contenido en Méndez Madariaga, A.; Rascón Marques, S. y Cuni, J., Reconstrucción de un ambiente de Estados; en Proyecto del Parque Etnoarqueológico Reina Sofía. Alcalá de Henares 1992 (inédito). 
son los bóvidos o incluso el camello. En todo caso la infraestructura disponible es susceptible de soportar un buen número de cabezas, ya que aunque sólo hay excavados tres ambientes se documenta un mínimo de siete.

Así, es difícil concretar la especie de ganado para el que se concibieron. Cabe pensar que el interés sentido por los propietarios de la villa hacia las carreras de caballos tenga alguna vinculación con sus actividades, y una presencia tan insistente del tema equino apuntaría de hecho a intereses que sobrepasarian el simple otium. No olvidemos que el mosaico del Auriga pavimenta el espacio más importante de la casa, siendo además un lugar de recepción donde se mostraria a los visitantes alguna actividad o acontecimiento que definan a la finca y sus propietarios. Por tanto y aun siendo imposible constatar este punto, es una hipótesis plausible la de pensar que una de las principales actividades económicas de la villa sería la ganadería equina vinculada a la cría de caballos para el circo, siendo por tanto nuestros establos empleados para ellos, si no todos, al menos sí una parte de los mismos. Otros argumentos que incidirían en ello son el tradicional uso de la zona de El Val como dehesa y la vecindad de espacios pantanosos o inundables. Recordemos que los caballos hispanos gozaron de una buena fama en el Imperio Romano, donde debieron tener una considerable demanda. Estos caballos necesitaron de una buena infraestructura que contemplase establos, campos para doma y entrenamiento y una buena cantidad de personal que asegurase que la cría era la adecuada para un uso tan específico como el que habrian de tener. Sin embargo hasta la fecha no se ha documentado ningún establecimiento que pudiera responder a este uso, aunque se ha intentado con la villa de Aguilafuente. Por desgracia el estudio de restos óseos no nos ayudará en nuestro caso, pues la muestra recuperada y sobre la que se ha realizado el análisis procede sobre todo de basureros, que probablemente son los últimos lugares donde se arrojarian los cadáveres de los veteranos corredores del circo.

Recordemos por último que en la Antigüedad los caballos hispanos parecen gozar de una cierta demanda motivada sin duda por una buena calidad (si bien no la mejor del Imperio), y que esto conllevaría la existencia de una serie de emplazamientos dedicados a la cría de caballos ${ }^{107}$.

107 Se ha escrito mucho sobre este tema. Recomendamos una reciente recopilación de Dafder, M. y Ripoll, G., "Caballos en la Antiguedad tardia hispánica",RA, 104. Madrid 1989, págs. 40-41. Sobre la famosa compra de caballos hispanos que realizó Simmaco, ver ARCE, J., "Los caballos de Simmaco". Faventia, 4, I. (1982), págs. 35-44. Las fuentes que se refieren a 


\section{CONCLUSIONES}

La decoración de tipo figurado que ha podido recuperarse en El Val alude sistemáticamente a las carreras de carros: un fragmento de encáustica que pertenece a una escena de tipo narrativo y un emblema de auriga vencedor correspondiente a un mosaico que parece desarrollar múltiples referencias al circo. Además de los paralelos iconográficos, los datos arqueológicos nos llevan a fecharlos en consonancia con la villa, en los últimos años del siglo II o primeros del iv d.C., relacionados con la época de la tetrarquía. Con respecto al mosaico hemos identificado una facturación compuesta, donde dos manos o dos talleres distintos ejecutan por separado el campo geométrico y el emblema. Pensamos en un equipo local para el primero, mientras que el segundo podría o no ser complutense, pero en todo caso no hay razones para pensar en un origen ajeno a la propia Hispania.

Las escenas circenses en general y las de aurigas vencedores en particular están cargadas de un simbolismo que en la mayoría de las veces pretende ser una invocación de la buena suerte. Sin embargo en el caso de El Val, aún cuando se mantenga esta idea, pensamos en una interpretación doble, que además explique la insistencia de la iconografía en estos temas y que contempla una referencia real a las carreras de carros. Así se conmemorarían victorias o espectáculos concretos con los que el propietario de la villa habría tenido relación, además de referir una actividad concreta. Unimos a esto la existencia de establos, la ubicación en un lugar adecuado para la ganadería equina y la frecuente demanda de caballos hispanos para espectáculos circenses que se experimentó en la Antigüedad, para formular la hipótesis de que una de las principales actividades económicas de El Val sea la cría de caballos de carreras.

Antes de terminar queremos agradecer la colaboración de Pedro Díaz del Río Español y Rosario Gómez Osuna, así como al asesoramiento de Dimas Fernández Galiano Ruiz y Gisela Ripoll López.

\section{ABREVIATURAS}

EHHVH:

Encuentro de Historiadores del Valle del Henares

RA: Revista de Arqueología

la consideración sobre las cuadras hispanas se recogen en varias publicaciones, la más reciente de las cuales es la de GuARDiA Pons, M., Op. cit., págs. 319 y ss., notas 29-33. 
CJ:

Cuadernos del Juncal. Serie de publicaciones del Taller Escuela de Arqueología y Rehabilitación de Alcalá de Henares

AA CC:

Anales Complutenses

APECM:

Arqueología, Paleontología y Etnografía en la Comunidad de Madrid

EAE:

Excavaciones Arqueológicas en España

CME:

Corpus de Mosaicos de España

MAAR:

Melanges d'Art et Archèologie

PV:

Príncipe de Viana

MEFRA:

Mélangés Ecole Française a Rome

CHAAN:

Colloque Histoire de l'Archeologie de I'Afrique du Nord

AJA:

R Arch.:

American Journal of Archeology

MP:

Revue Archéologique

BA:

Melanges Picard

INAAT:

Bellas Artes

EFR:

Institute National d'Archéologie et d'Art de Tunis

BRAH:

Ecole Française de Rome

BAA:

Boletín de la Real Academia de la Historia Bulletín d'Archéologie Algérien. Republique Algérienne Democratique et Populaire. Ministère de l'Education Nationale

ME: Monografías Emeritenses. Museo Nacional de Arte Romano de Mérida 